Mycologia, 103(6), 2011, pp. 1384-1410. DOI: 10.3852/11-006

(C) 2011 by The Mycological Society of America, Lawrence, KS 66044-8897

\title{
Novel species of Celoporthe from Eucalyptus and Syzygium trees in China and Indonesia
}

\section{ShuaiFei Chen}

Department of Microbiology and Plant Pathology, Forestry and Agricultural Biotechnology Institute (FABI), University of Pretoria, Pretoria 0002, South Africa, and China Eucalypt Research Centre (CERC), Chinese Academy of Forestry (CAF), Zhanjiang, 524022, GuangDong Province, China

Marieka Gryzenhout

Jolanda Roux

Department of Microbiology and Plant Pathology, Forestry and Agricultural Biotechnology Institute (FABI), University of Pretoria, Pretoria 0002, South Africa

YaoJian Xie

China Eucalypt Research Centre (CERC), Chinese Academy of Forestry (CAF), ZhanJiang 524022, GuangDong Province, China

Michael J. Wingfield

Department of Microbiology and Plant Pathology, Forestry and Agricultural Biotechnology Institute (FABI), University of Pretoria, Pretoria 0002, South Africa

XuDong Zhou ${ }^{1}$

Department of Microbiology and Plant Pathology, Forestry and Agricultural Biotechnology Institute (FABI), University of Pretoria, Pretoria 0002, South Africa, and China Eucalypt Research Centre (CERC), Chinese Academy of Forestry (CAF), Zhanjiang 524022, GuangDong Province, China

Abstract: Many species in the Cryphonectriaceae cause diseases of trees, including those in the genera Eucalyptus and Syzygium. During disease surveys on these trees in southern China, fruiting structures typical of fungi in the Cryphonectriaceae and associated with dying branches and stems were observed. Morphological comparisons suggested that these fungi were distinct from the well known Chrysoporthe deuterocubensis, also found on these trees in China. The aim of this study was to identify these fungi and evaluate their pathogenicity to Eucalyptus clones/species as well as Syzygium cumini. Three morphologically similar fungal isolates collected previously from Indonesia also were included in the study. Isolates were characterized based on comparisons of morphology and DNA sequence data for the partial LSU and ITS nuclear ribosomal DNA, $\beta$ tubulin and TEF-1 $\alpha$ gene regions. After glasshouse

Submitted 5 Jan 2011; accepted for publication 19 Apr 2011.

${ }^{1}$ Corresponding author. E-mail: xu.zhou@fabi.up.ac.za OR cerc. zhou@gmail.com trials to select virulent isolates field inoculations were undertaken to screen different commercial Eucalyptus clones/species and S. cumini trees for susceptibility to infection. Phylogenetic analyses showed that the Chinese isolates and those from Indonesia reside in a clade close to previously identified South African Celoporthe isolates. Based on morphology and DNA sequence comparisons, four new Celoporthe spp. were identified and they are described as C. syzygii, $C$. eucalypti, C. guangdongensis and C. indonesiensis. Field inoculations indicated that the three Chinese Celoporthe spp., C. syzygii, C. eucalypti and C. guangdongensis, are pathogenic to all tested Eucalyptus and S. cumini trees. Significant differences in the susceptibility of the inoculated Eucalyptus clones/ species suggest that it will be possible to select diseasetolerant planting stock for forestry operations in the future.

Key words: Cryphonectriaceae, Myrtales, plantation forestry, southeastern Asia, stem canker pathogens

\section{INTRODUCTION}

The Cryphonectriaceae Gryzenh. \& M.J. Wingf. (Diaporthales) represents a group of bark and/or wood-infecting fungi of trees and shrubs in various parts of the world (Gryzenhout et al. 2009). Species of Cryphonectriaceae exist naturally as virulent pathogens, facultative parasites or saprophytes on woody hosts. Some species have been introduced into new environments, causing diseases on important trees, such as those grown commercially in plantations or for their ornamental value, and include some of the most important tree pathogens in the world (Gryzenhout et al. 2009). Except for Cryphonectria (Sacc.) Sacc. \& D. Sacc., which is the type genus, 13 other genera have been described in this family (Nakabonge et al. 2006a; Cheewangkoon et al. 2009; Gryzenhout et al. 2009, 2010; Begoude et al. 2010; Vermeulen et al. 2011).

Several species of Cryphonectriaceae had been collected from trees in China. Cryphonectria parasitica (Murrill) M.E. Barr, best known for causing a devastating canker disease of chestnuts (Castanea spp.) in USA and Europe (Anagnostakis 1987, 1992), also causes cankers and dieback on Chinese chestnut (Castanea mollissima Blume) trees in their native range (Fairchild 1913; Shear and Stevens 1913, 1916). 
Cryphonectria japonica (Tak. Kobay. \& Kaz. Itô) Gryzenh. \& M.J. Wingf. (=Cryphonectria nitschkei [G.H. Otth] M.E. Barr), which first was collected in Japan, and Endothia gyrosa (Schwein.: Fr.) Fr. have been found on a Quercus sp. in China (Teng 1934, Kobayashi and Itô 1956, Myburg et al. 2004, Gryzenhout et al. 2009). Chrysoporthe deuterocubensis Gryzenh. \& M.J. Wingf., treated as Chr. cubensis (Bruner) Gryzenh. \& M.J. Wingf. (van der Merwe et al. 2010), has been reported from species of Eucalyptus and Syzygium in southern China from a wide range of locations (Sharma et al. 1985, Hodges et al. 1986, Myburg et al. 2002, Zhou et al. 2008, Chen et al. 2010).

The genus Celoporthe Nakab., Gryzenh., Jol. Roux \& M.J. Wingf., based on C. dispersa Nakab., Gryzenh., Jol. Roux \& M.J. Wingf., is a recently described genus in the Cryphonectriaceae, reported from dying branches and stems on both native and introduced Myrtales in South Africa (Nakabonge et al. 2006a). Celoporthe is monotypic, but phylogenetic analyses have shown that it is composed of three distinct phylogenetic clades (Nakabonge et al. 2006a). C. dispersa is represented by isolates from native Syzygium cordatum Hochst.: C.Kraus, native Heteropyxis canescens Oliv. and non-native Tibouchina granulosa Cogn. (Nakabonge et al. 2006a) in South Africa. Based on DNA sequence comparisons, isolates collected from Syzygium aromaticum (L.) Merr. \& L.M. Perry in Indonesia (Myburg et al. 2003) also grouped closely with $C$. dispersa, but morphological evaluation was impossible because relative herbarium material does not exist (Myburg et al. 2003).

During surveys in southern China for pathogens of trees in the Myrtaceae, especially species of Eucalyptus and Syzygium, several species affecting these trees were identified (Zhou et al. 2008). In addition to Chr. deuterocubensis (Chen et al. 2010) these surveys yielded a fungus on Eucalyptus and S. cumini trees resembling $C$. dispersa. The aim of the present study was to characterize these isolates based on morphology and phylogenetic analyses and to assess their pathogenicity to Eucalyptus and S. cumini with glasshouse and field inoculations.

\section{MATERIALS AND METHODS}

Sampling.-Eucalyptus (Myrtales) plantations in the GuangDong Province of southern China were investigated for the presence of fungal diseases Nov-Dec 2006, Jan 2007 and Sep-Nov 2008. Where present in these areas S. cumini trees (Myrtales) also were examined for the presence of fungi in the Cryphonectriaceae because these fungi are known to occur on Syzygium spp. (Heath et al. 2006, Gryzenhout et al. 2009). Sections of bark bearing fruiting structures (ascostromata and conidiomata) resembling the Cryphonectria- ceae were collected from symptomatic trees and transported to the laboratory to make isolations.

Samples were incubated in moist chambers 1-3 $d$ to induce the production of spores from the fruiting bodies. Single tendrils of spores were transferred to $2 \%$ malt extract agar (MEA) (Biolab, Merck, Midrand, South Africa) (20 g Biolab malt extract, $20 \mathrm{~g}$ Biolab agar, $1 \mathrm{~L}$ water) and incubated at 25 C. Single hyphal tips were transferred to fresh $2 \%$ MEA to obtain pure cultures. Three unidentified isolates from Indonesia, originating from $S$. aromaticum and resembling fungi in the Cryphonectriaceae, obtained from the culture collection (CMW) of the Forestry and Agricultural Biotechnology Institute (FABI), University of Pretoria, South Africa, also were included in this study (TABLE I). All cultures collected from China are maintained in the culture collection (CMW), and a duplicate set of isolates is maintained in a culture collection at the China Eucalypt Research Centre (CERC), Chinese Academy of Forestry (CAF), China. Representative isolates also were deposited with the Centraalbureau voor Schimmelcultures (CBS), Utrecht, the Netherlands (TABLE I). The original bark bearing fruiting structures was deposited in the National Collection of Fungi (PREM), Pretoria, South Africa.

DNA extraction, PCR and sequencing reactions.-Isolates originating from different Eucalyptus species/clones and $S$. cumini from the various areas sampled, as well as those showing differing culture and fruiting structure morphology (TABLE I), were selected for DNA sequence comparisons. Before DNA extraction, isolates were grown in 2\% MEA at $25 \mathrm{C}$ for $5-7 \mathrm{~d}$. For each isolate actively growing mycelium from one MEA plate per isolate was scraped from the surface of the medium with a sterile scalpel and transferred to $1.5 \mathrm{~mL}$ Eppendorf tubes. Genomic DNA was extracted with the method described by Myburg et al. (1999), separated by electrophoresis on a $1 \%$ agarose gel, stained with ethidium bromide and viewed under ultraviolet (UV) light. Samples were treated with $3 \mu \mathrm{L}$ RNase $(1 \mathrm{mg} / \mathrm{mL})$ and left overnight at $37 \mathrm{C}$ to degrade RNA.

Gene regions amplified with the polymerase chain reaction (PCR) included the conserved nuclear large subunit (LSU) ribosomal DNA, the $\beta$-tubulin gene region 1 (BT1) and 2 (BT2), the internal transcribed spacer (ITS) regions including the $5.8 \mathrm{~S}$ gene of the ribosomal DNA operon as well as the translation elongation factor 1-alpha (TEF-1 $\alpha$ ) gene region. Part of the LSU rDNA gene region was amplified with primers LR0R and LR7 (Vilgalys and Hester 1990, Rehner and Samuels 1994); two regions within the $B T$ gene were amplified respectively with primer pairs $\beta \mathrm{t} 1 \mathrm{a} / \beta \mathrm{t} 1 \mathrm{~b}$ and $\beta \mathrm{t} 2 \mathrm{a} / \beta \mathrm{t} 2 \mathrm{~b}$ (Glass and Donaldson 1995); the ITS regions including the $5.8 \mathrm{~S}$ rDNA operon were amplified with the primer pair ITS1 and ITS4 (White et al. 1990); and a fragment of the $T E F-1 \alpha$ gene region was amplified with primer pairs EF1-728F and EF1-986R (Carbone and Kohn 1999). PCR conditions for the LSU gene region were as outlined by Castlebury et al. (2002); those for the BT1/2 and ITS gene regions followed the protocols of Myburg et al. (2002); and the $T E F-1 \alpha$ gene region was amplified with the method described by Slippers et al. (2004). PCR products were viewed with UV light on $1 \%$ agarose 


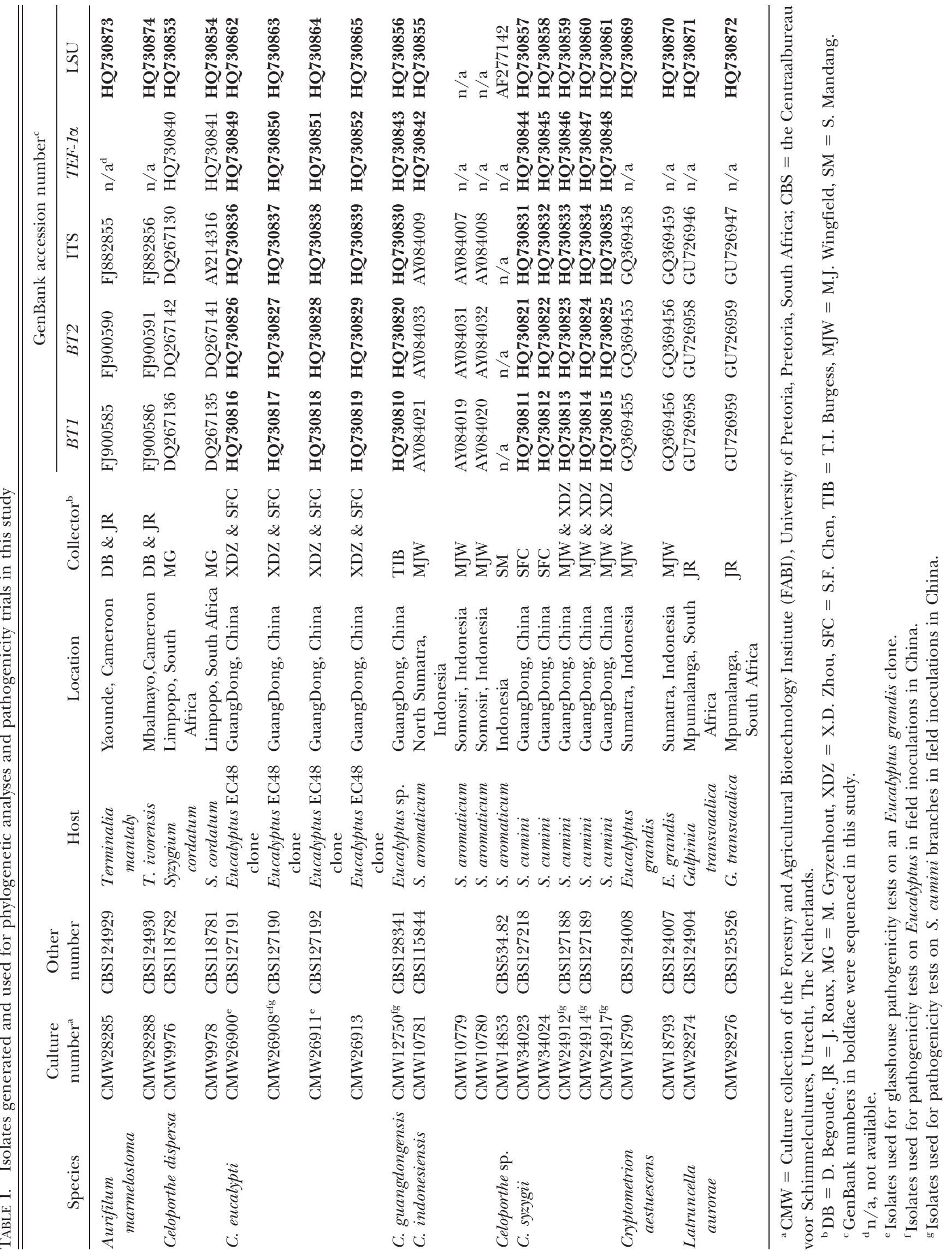


(ethidium bromide-stained) gels. Amplified products were purified as suggested by the manufacturers with $6 \%$ Sephadex G-50 columns (Steinheim, Germany).

Each PCR product was sequenced in both directions with the same primers used for PCR reactions. The ABI PRISM ${ }^{\mathrm{TM}}$ Big Dye Terminator Cycle Sequencing Ready Reaction Kit 3.1 (Applied Biosystems, Foster City, California) was used to perform the sequencing reactions. Sephadex G-50 columns $(6 \%)$ were used to purify the sequence products, whereafter electropherograms were generated on an ABI PRISM 3100 autosequencer (Perkin-Elmer Applied Biosystems, Foster City, California). Nucleotide sequences were edited with MEGA4 (Tamura et al. 2007). All sequences obtained in this study were deposited in GenBank (TABLE I).

Phylogenetic analyses. - To determine the generic placement of the isolates collected from Eucalyptus and S. cumini in southern China, as well as those previously collected in Indonesia, sequences of the LSU gene region were analyzed. These were supplemented by analyses of the conserved 5.8S rDNA and the exon regions of the $B T$ (including partial exon 4, exon 5, partial exon 6 and partial exon 7) gene regions for previously described species in the Cryphonectriaceae (Gryzenhout et al. 2009, Begoude et al. 2010, Gryzenhout et al. 2010, Vermeulen et al. 2011). The datasets of Gryzenhout et al. (2006a, 2009) were used as templates for analyses of the LSU. Togninia minima (Tul. \& C. Tul.) Berl., T. fraxinopennsylvanica (T.E. Hinds) Georg Hausner, Eyjólfsd. \& J. Reid and Phaeoacremonium aleophilum W. Gams, Crous, M.J. Wingf. \& Mugnai were used as outgroups (Gryzenhout et al. 2009). Two isolates of Diaporthe ambigua Nitschke were used as outgroups for analyses of the $5.8 \mathrm{~S}$ gene and BT exon regions (Gryzenhout et al. 2009). The partition homogeneity test (PHT) as implemented in PAUP* 4.0b10 (Swofford 2002) was used to determine whether conflict existed between the datasets for these two gene regions (Farris et al. 1995, Huelsenbeck et al. 1996) before performing combined analyses in PAUP*.

To determine the species identities and phylogenetic relationships among the isolates from China and previously described species of Cryphonectriaceae sequences of the $B T 1, B T 2$, ITS and $T E F-1 \alpha$ gene regions were analyzed separately and in combination. The partition homogeneity test (PHT) in PAUP $4.0 \mathrm{~b} 10$ also was used to determine whether conflict existed among the three datasets.

All sequences were aligned with the iterative refinement method (FFT-NS-i settings) of the online version of MAFFT 5.667 (Katoh et al. 2002) and edited manually where necessary in MEGA4 (Tamura et al. 2007). The sequence alignments for each of the datasets were deposited in TreeBASE (http://www.treeBASE.org). Three different phylogenetic analyses were conducted for each of the datasets. Maximum parsimony (MP) analyses were performed with PAUP* 4.0b10, maximum likelihood (ML) tests were conducted with PhyML 3.0 (Guindon and Gascuel 2003), and Bayesian analysis with the Markov chain Monte Carlo (MCMC) algorithm were performed as implemented in MrBayes 3.1.2 (Ronquist and Huelsenbeck 2003).

For MP analyses gaps were treated as a fifth character and the characters were unordered and of equal weight with
1000 random addition replicates. The most parsimonious trees were obtained with the heuristic search function and tree bisection and reconstruction (TBR) as branch swapping algorithms. MAXTREEs were unlimited and branch lengths of zero were collapsed. A bootstrap analysis (50\% majority rule, 1000 replicates) was done to determine the confidence levels of the tree-branching points (Felsenstein 1985). Tree length (TL), consistency index (CI), retention index (RI) and the homoplasy index (HI) were used to assess the trees (Hillis and Huelsenbeck 1992). For ML and Bayesian analyses of each dataset the best models of nucleotide substitution were established respectively with Modeltest 3.7 (Posada and Crandall 1998) and MrModeltest 2.3 (Nylander 2004). For the ML analyses additional ML parameters in PhyML included the retention of the maximum number of 1000 trees and the determination of nodal support by non-parametric bootstrapping with 1000 replicates. For Bayesian analyses four chains were run simultaneously for the MCMC analyses over 1000000 generations. After every 100th generation trees were saved. The burn-in number was established graphically from likelihood scores, and the posterior probabilities $(50 \%$ majority rule) were determined from the remaining trees. MEGA4 was used to construct consensus trees (Tamura et al. 2007).

Morphology.-Only herbarium samples from S. cumini were available for detailed study, and collections from Eucalyptus species/clones were available only as cultures. Asexual structures of the Cryphonectriaceae are not always produced, and sexual states are almost never induced in culture. For these reasons thin branches of E. grandis and $S$. cordatum, a native species of Myrtaceae in South Africa, were used to induce the production of fruiting structures. Freshly cut branch sections $(1-2 \mathrm{~cm}$ diam $\times 15 \mathrm{~cm}$ long) of E. grandis and $S$. cordatum were inoculated artificially under glasshouse conditions with nine single-conidial isolates (CWM10781, CWM12750, CWM24912, CWM24914, CWM24917, CWM26900, CWM26908, CWM26911, CWM26913) that originated from different hosts and locations in China and Indonesia (TABLE I).

Before inoculation branch sections were surface disinfested by swabbing with $75 \%$ alcohol. Each section was inoculated by removing a $7 \mathrm{~mm}$ diam cambial disk with a cork borer and placing a disk of equivalent size from a $7 \mathrm{~d}$ old MEA culture of these fungi into the wound. Sterile MEA disks were placed in wounds, and these served as controls. Each inoculated wound was covered with parafilm (Pechiney Plastic Packing, Chicago, Illinois). In one method the top ends of the sections were coated with melted paraffin and the other ends were placed in containers of water to ensure that the sections continued to absorb water. In a second method both ends of the branch sections were coated with melted paraffin and the inoculated sections were placed in covered plastic boxes on damp paper towels. Three replicates of each treatment were made, including six branches each of an E. grandis clone and $S$. cordatum inoculated with each isolate. All inoculated branch sections were incubated at $25 \mathrm{C}$. After 6 mo incubation fruiting structures formed on the bark were examined. 


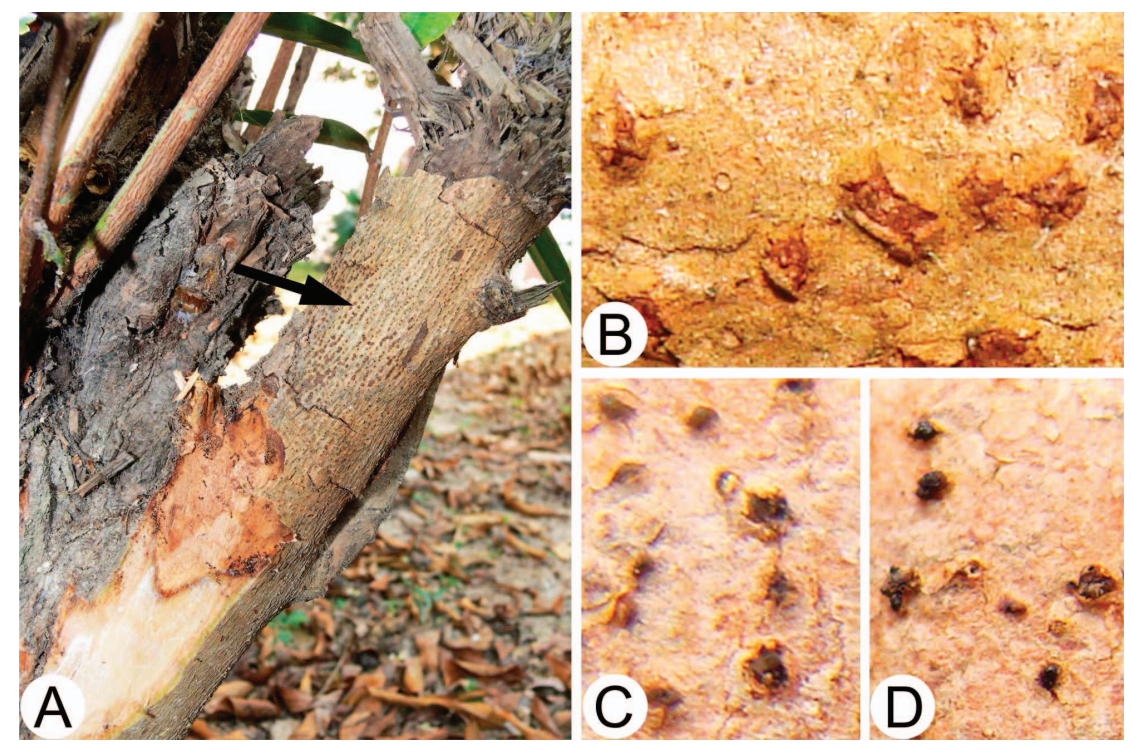

Fig. 1. Symptoms of infection on $S$. cumini trees caused by C. syzygii, as well as inoculated branches of $S$. cordatum and an E. grandis clone with isolates of a C. syzygii. A. Cracks and cankers on S. cumini trees caused by C. syzygii (arrow indicates fruiting structures). B. Fruiting structures of C. syzygii on bark of S. cumini. C. Conidiomata of C. syzygii on inoculated branches of S. cordatum. D. Conidiomata of C. syzygii on inoculated branches of an E. grandis clone.

To obtain an indication of the minimum and maximum size ranges of the stromata measurements were made from both anamorph and telemorph structures on Eucalyptus and $S$. cumini bark. To study the internal morphology of the fungi collected fruiting structures were cut from the original field collected, as well as glasshouse-generated bark specimens under a dissection microscope, boiled 2 min and sectioned (12 $\mu \mathrm{m}$ thick) with a Leica CM1100 cryostat (Setpoint Technologies, Johannesburg, South Africa) at -20 C (Gryzenhout et al. 2004). To study the asci, ascospores, conidiophores, conidiogenous cells and conidia fruiting structures were crushed on microscope slides in $85 \%$ lactic acid or $3 \% \mathrm{KOH}$. For the holotype specimen 50 measurements were made for each of these characteristics, while 20 measurements per character were made for the remaining specimens. A HRc Axiocam digital camera with Axiovision 3.1 software (Carl Zeiss Ltd., Germany) was used to capture images and to obtain measurements. Characteristics of specimens were compared with those published for closely related species in the Cryphonectriaceae (Gryzenhout et al. 2009, Begoude et al. 2010, Gryzenhout et al. 2010, Vermeulen et al. 2011). The results were presented as (min-) $($ mean - st.dev. $)-($ mean + st.dev. $)(-$ max $)$.

For studies of culture characteristics five representative isolates (CMW34023, CMW34024, CMW24912, CMW24914, CMW24917) from S. cumini, four isolates (CMW26900, CMW26908, CMW26911, CMW26913) from an Eucalyptus clone, one isolate (CMW12750) from an Eucalyptus sp., as well as an isolate (CMW10781) from $S$. aromaticum in Indonesia, were used. Isolates were incubated on 2\% MEA at $25 \mathrm{C}$ for $7 \mathrm{~d}$. Mycelial plugs $(6 \mathrm{~mm}$ ) were taken from the actively growing margins of these cultures and transferred to the centers of $90 \mathrm{~mm}$ Petri dishes containing 2\% MEA. These were incubated at 5-35 $\mathrm{C}$ at 5 degree intervals with four replicates of each isolate at every temperature. Two measurements perpendicular to each other were taken daily until the fastest growing culture had covered the plate. Averages were computed for each temperature with Microsoft Excel 2003. The entire experiment was repeated once. Color designations were obtained for the descriptions of cultures and fruiting bodies with the charts of Rayner (1970).

Pathogenicity tests.-Glasshouse trials. Three isolates (CMW26900, CMW26908, CMW26911) from an Eucalyptus clone in China (TABLE I) were selected for inoculations. These isolates represented a subset of a larger collection of one of the clades identified by DNA sequence comparisons. To select the most virulent isolates for field inoculations in China the three isolates were inoculated on trees of a susceptible $E$. grandis clone (TAG-5) in the glasshouse. The trees were approximately $2 \mathrm{~m}$ tall by $\sim 10 \mathrm{~mm}$ diam. Before conducting inoculations all the trees were allowed to adapt to the glasshouse environment of $25 \mathrm{C}$ with $14 \mathrm{~h}$ daylight and $10 \mathrm{~h}$ darkness approximately $1 \mathrm{mo}$. Before inoculation the three isolates were grown at $25 \mathrm{C}$ under continuous fluorescent light $6 \mathrm{~d}$.

Wounds were made on tree bark at the same height $(\sim 300 \mathrm{~mm}$ above the medium $)$ with a cork borer $(7 \mathrm{~mm}$ diam) to expose the cambium. Agar disks, $7 \mathrm{~mm}$ diam, were taken from the margins of actively growing fungal cultures and placed into the wounds with the mycelium facing the exposed cambium. To prevent contamination and desiccation wounds were covered with parafilm. Each of the three isolates was inoculated into the stems of 10 trees. For the negative controls 10 trees were inoculated with sterile MEA plugs. The 40 inoculated trees were arranged randomly in a single glasshouse.

After $6 \mathrm{wk}$, lesion lengths in the cambium were measured. Small pieces of discolored xylem were taken from four 

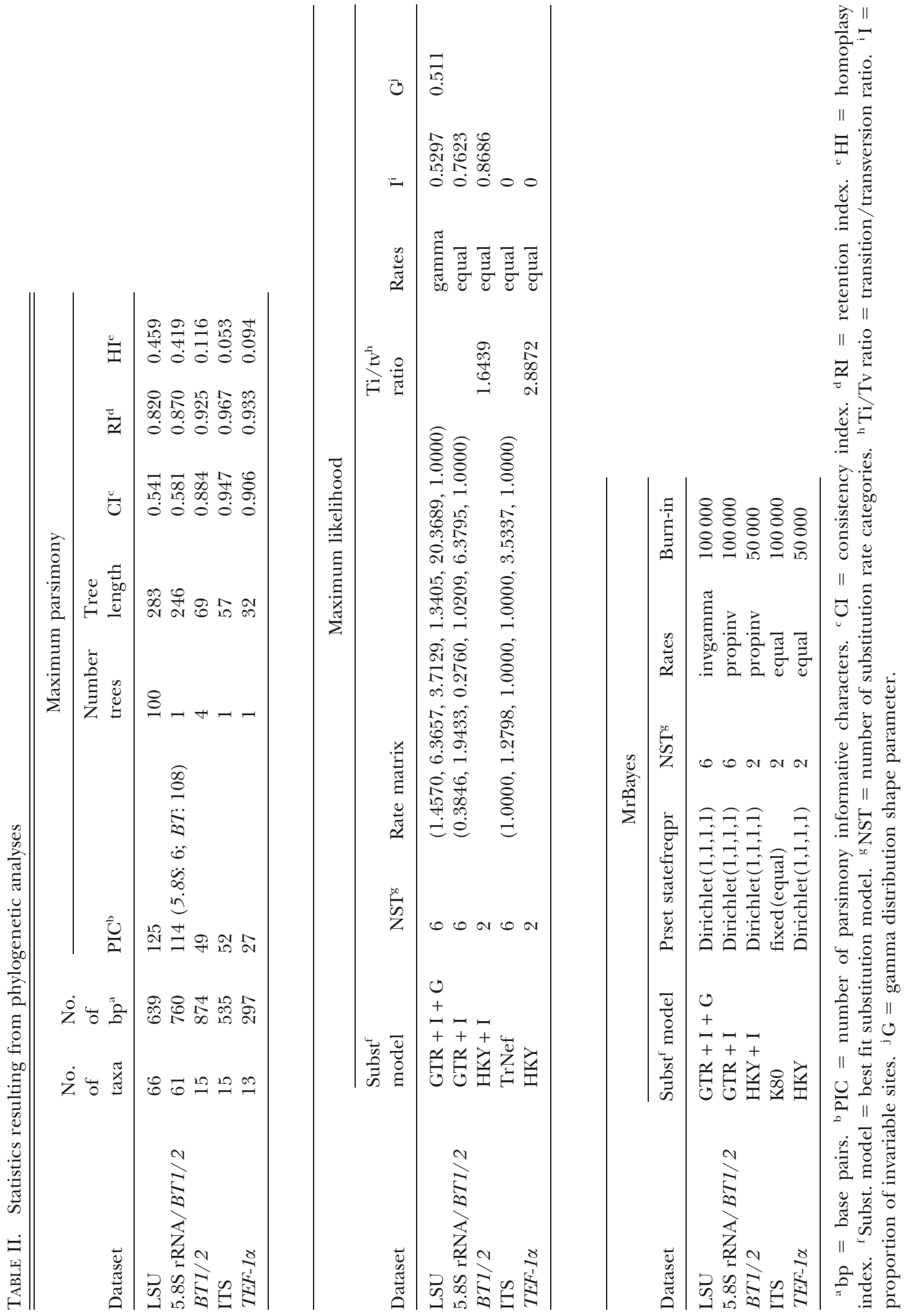


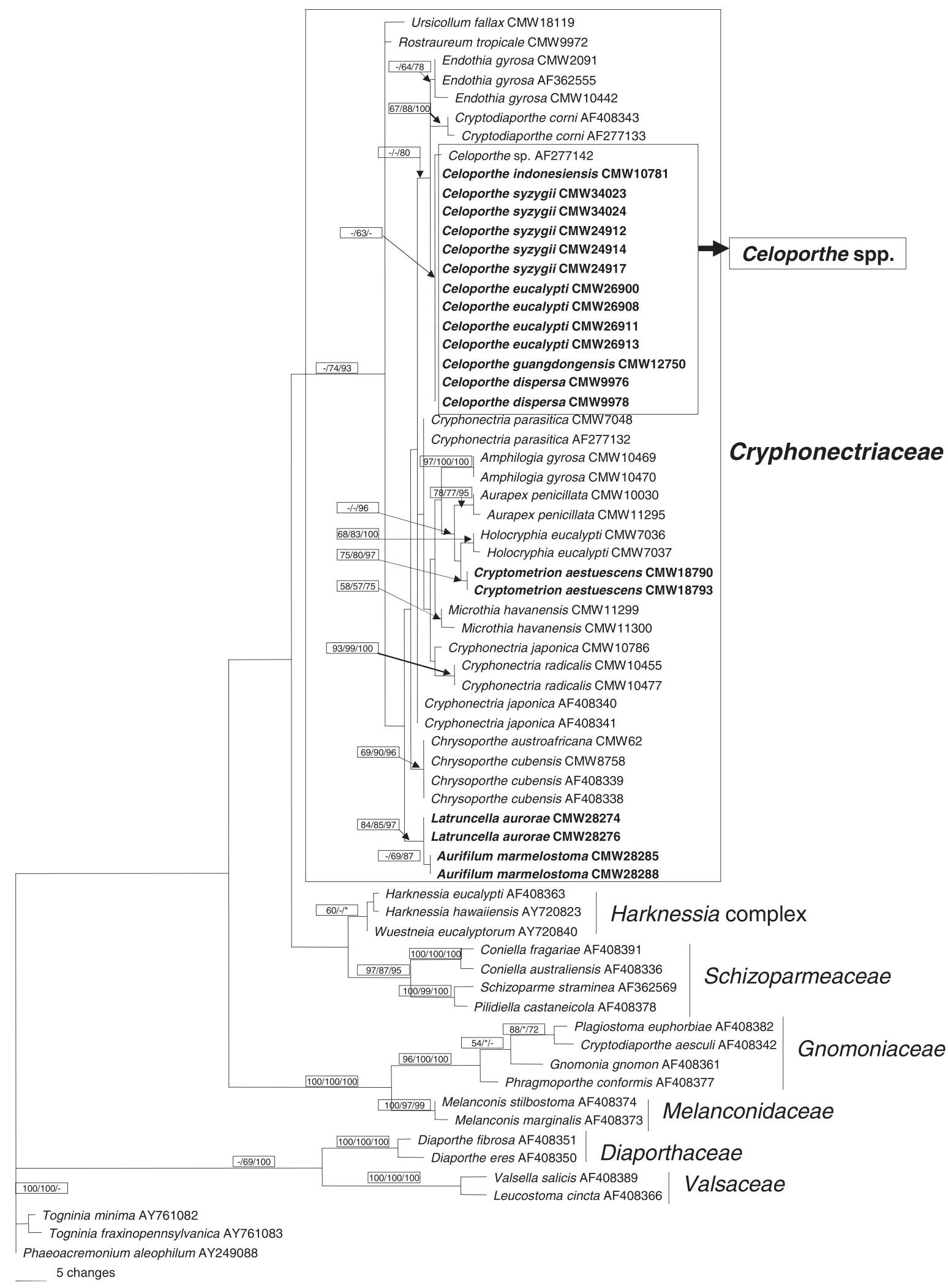

FIG. 2. Cladogram based on maximum parsimony (MP) analysis of LSU DNA sequences for various genera in the Diaporthales. Isolates in boldface were sequenced in this study. Sequences with AF and AY numbers originated from Zhang and Blackwell (2001) and Castlebury et al. (2002), while others were obtained from Gryzenhout et al. (2006a, 2009). Bootstrap values $>50 \%$ for MP and maximum likelihood (ML), and posterior probabilities $>70 \%$ obtained from Bayesian analyses are 
randomly selected trees for each isolate as well as all the trees inoculated as controls, placed onto the surface of $2 \%$ MEA and incubated at 25 C. In this way it was possible to ascertain that the inoculated fungi were responsible for causing the lesions.

The results of the inoculations were analyzed in SAS 8 with PROC GLM (general linear model) (SAS Institute 1999). To determine the effects of the fungal strains on lesion length, analysis of variance (ANOVA) was conducted. Before ANOVA homogeneity of variance across treatments was confirmed. Fisher's protected test was used to determine the significance among means and $P<0.05$ for the $\mathrm{F}$ value taken as significant in difference.

Field trials. For the field inoculations isolate CMW26908, selected based on the results of the greenhouse trial and isolate CMW12750 also from Eucalyptus, were used to test the susceptibility of commercially grown Eucalyptus species and clones in southern China (TABLE I). In addition, to compare the aggressiveness of isolates collected from S. cumini with the isolates from Eucalyptus trees three isolates (CMW24912, CMW24914, CMW24917) collected from S. cumini in China (TABLE I) were used. The five isolates selected for field inoculations thus represented three different phylogenetic clades emerging from the DNA sequence comparisons.

Seven Eucalyptus genotypes, including hybrids and pure species, were selected for field-inoculation trials. The genotypes included an E. grandis clone (CEPT-1), an E. grandis $\times E$. tereticornis $\mathrm{Sm}$. clone (CEPT-2), an E. pellita F.Muell genotype (CEPT-3), two E. urophylla S.T.Blake $\times E$. grandis clones (CEPT-4, CEPT-7), an E. urophylla clone (CEPT-5) and an E. wetarensis L.D.Pryor clone (CEPT-6). Isolates CMW12750 and CMW26908 were inoculated on all seven Eucalyptus genotypes. Because there were a limited number of Eucalyptus trees available for inoculation the isolates (CMW24912, CMW24914, CMW24917) collected from $S$. cumini trees were inoculated only onto Eucalyptus genotypes CEPT-6 and CEPT-7.

Inoculated trees were approximately $1 \mathrm{y}$ old at the time of the experiment. For each isolate 6-10 trees of each genotype were inoculated. For the negative controls 10 trees were inoculated with sterile MEA disks. Inoculations were made with a $9 \mathrm{~mm}$ diam cork borer to remove the bark and expose the cambium at the same height $(\sim 400$ $800 \mathrm{~mm}$ ) above the ground. Agar disks taken from the actively growing margins of the test isolates were placed in the wounds with the mycelium facing the cambium. In the case of the negative controls, sterile MEA was used. All inoculation wounds were covered with masking tape to reduce contamination and desiccation of the inoculum.

To test the susceptibility of $S$. cumini trees to the fungi isolated from southern China, and also to compare the aggressiveness of isolates collected from Syzygium trees with those from Eucalyptus on S. cumini, the same isolates
(CMW12750， CMW26908， CMW24912, CMW24914, CMW24917) as those used for the Eucalyptus field tests also were inoculated onto branches of healthy S. cumini trees (TABLE I). Ten branches were inoculated for each of the five selected isolates, and $10 \mathrm{~S}$. cumini branches were inoculated with sterile MEA as negative controls. Inoculations were conducted with a method similar to that for the Eucalyptus genotype inoculation trials. The entire trial was repeated once.

The field trials were conducted Sep-Oct 2008 in ZhanJiang, GuangDong Province, China. After 5 and 6 wk of inoculations on Eucalyptus trees and the S. cumini branches respectively lesion lengths in the cambium of the trees were measured. Data for lesion length were analyzed with PROC GLM (general linear model) in SAS (SAS Institute 1999) in a manner similar to that for the greenhouse inoculations.

\section{RESULTS}

Sampling.-Disease surveys on Eucalyptus and $S$. cumini trees in GuangDong Province revealed typical symptoms of infection by fungi in the Cryphonectriaceae. These included cracking of the bark and the formation of girdling stem cankers (FIG. 1A, B). Apart from symptoms caused by Chr. deuterocubensis (Chen et al. 2010), anamorph and teleomorph fruiting structures of a fungus resembling $C$. dispersa were observed on diseased bark of Eucalyptus and S. cumini trees. These fruiting structures (anamorph and teleomorph) often were completely orange with orange to umber perithecial necks, and they could be distinguished from fruiting structures of Chr. deuterocubensis that were always fuscous black to umber, with black and much longer perithecial necks (Gryzenhout et al. 2009, Chen et al. 2010). Ascostromata and conidiomata of the unknown fungus often were found on the cankers on the S. cumini trees, while only conidiomata were observed on Eucalyptus trees. Isolates were obtained from two $S$. cumini trees, one tree of an unknown Eucalyptus sp. and one tree representing Eucalyptus clone EC48 (TABLE I).

Phylogenetic analyses._-Generic placement. The aligned sequences of the LSU dataset consisted of 66 taxa and 639 characters (TreeBASE: http://purl.org/phylo/ treebase/phylows/study/TB2:S11111). Statistical values for obtained trees for the parsimony analysis, number of informative characters and parameters for the best

$\leftarrow$

presented above branches as follows: MP/ML/Bayesian. Bootstrap values lower than 50\%, and posterior probabilities lower than $70 \%$ are marked with $*$, and absent analysis values are marked with -. Togninia minima (AY761082), T. fraxinopennsylvanica (AY761083) and Phaeoacremonium aleophilum (AY249088) in the family Togniniaceae represent the outgroups. 
fit substitution models are provided (TABLE II). For maximum parsimony (MP), maximum likelihood (ML) and Bayesian analyses the position of the genera in relation to each other was different, but genera still could be distinguished consistently from each other. A total of 100 most parsimonious trees were obtained after analyses of the LSU dataset, of which the first tree was saved (FIG. 2). Isolates collected from Eucalyptus and $S$. cumini trees in China and S. aromaticum in Indonesia clearly resided in the genus Celoporthe, with Celoporthe representing a distinct lineage in the Cryphonectriaceae (FIG. 2) $($ ML bootstrap $=63 \%)$.

The partition homogeneity test (PHT) comparing the exons in the $B T$ gene region and the 5.8S rRNA gene datasets gave a PHT value of $P=0.988$, indicating that these two datasets do not have a significant conflict and could be combined in the phylogenetic analyses. The aligned sequences of the combined datasets consisted of 61 taxa and 760 characters (TreeBASE: http://purl.org/phylo/ treebase/phylows/study/TB2:S11111) (TABLE II). Similar to results of the LSU dataset, the position of the genera in relation to each other differed slightly based on the three different analyses, but the topology was similar for the genera. Results showed that all genera in the Cryphonectriaceae resided in discrete clades with high support values in at least one of the three analyses (FIG. 3). Only one most parsimonious tree was obtained (FIG. 3). Based on the phylogenetic analyses of the combined $B T$ exons and 5.8S gene sequences, the isolates from Eucalyptus and Syzygium trees in China and Indonesia grouped closely with those of $C$. dispersa and separately from other genera in the Cryphonectriaceae (MP bootstrap $=87 \%$, ML bootstrap $=89 \%$, Bayesian posterior probabilities $=100 \%$ ) (FIG. 3). Within the Celoporthe clade the isolates from Asia (China and Indonesia) formed several clades separate from that representing C. dispersa from South Africa (MP bootstrap $=92 \%$, ML bootstrap $=71 \%$, Bayesian posterior probabilities =99\%) (FIG. 3).

Species identification. The LSU phylogenetic analyses and BLAST queries for the BT and ITS gene sequences showed that the isolates considered in this study were phylogenetically most closely related to Celoporthe spp. The type species of this genus, $C$. dispersa (Nakabonge et al. 2006a), and Celoporthe isolates (CMW10779, CMW10780, CMW10781) collected from $S$. aromaticum trees in Indonesia (Myburg et al. 2003, Nakabonge et al. 2006a) were included with the isolates collected from China for species identification. The partition homogeneity test (PHT) comparing the $B T$, ITS and TEF- $1 \alpha$ datasets gave a PHT value of $P=0.998$, indicating that these three datasets do not have a significant conflict and could be combined for phylogenetic analyses. This was supported by the topologies of the separate trees of the three gene datasets and the combination datasets that consistently showed the same phylogenetic groups (FIG. 4A-C).

Where the three datasets (TreeBASE: http://purl. org/phylo/treebase/phylows/study/TB2:S11111) were analyzed separately, four equally most parsimonious trees were obtained for the two $B T$ gene regions (FIG. 4A) while one most parsimonious tree was obtained respectively for the ITS (FIG. 4B) and TEF-1 $\alpha$ (FIG. 4C) datasets. Results for all three gene regions showed that the Asian isolates are distinct from $C$. dispersa, with long phylogenetic branch distances and high support values (branch distances 17-42; MP bootstrap value $100 \%$ for each of the three genes) (FIG. 4A-C). The phylogenetic analyses for each of the $B T$, ITS and TEF- $1 \alpha$ gene regions further showed that the Asian isolates formed four clades supported by long phylogenetic branch distances and high support values (branch distances up to 6; MP bootstrap value up to $100 \%$; ML bootstrap value up to $99 \%$; Bayesian posterior probabilities up to $100 \%)$. In these clades isolates (CMW24912, CMW24914, CMW24917, CMW34023, CMW34024) from $S$. cumini trees in China formed a single clade, isolates (CMW26900, CMW26908, CMW26911, CMW26913) from a Chinese Eucalyptus clone formed a second clade, one isolate (CMW12750) from a Chinese Eucalyptus sp. resided in a third clade and isolates (CMW10779, CMW10780, CMW10781) from $S$. aromaticum trees in Indonesia formed the fourth (FIG. 4A-C).

Single nucleotide polymorphism (SNP) analyses supported the distinction of four clades for the Asian (Chinese and Indonesian) Celoporthe isolates considered in this study. Unique SNPs could be identified for all four phylogenetic groups for each of the gene regions sequenced (TABLES III, IV). Comparisons of the three gene regions showed that each clade was separated from the other three clades by 4-11 unique SNPs for each gene region (TABLE III). The total number of SNP differences between the four clades for all three gene regions combined varied between 21-31 unique SNPs (TABLE IV). No nucleotide differences could be detected in the $B T$, ITS and $T E F-1 \alpha$ gene regions for the isolates within each of the three Chinese Celoporthe clades. In the Indonesian Celoporthe clade some nucleotide differences in the $B T$ (10 bp) and ITS (12 bp) regions were found between isolate CWM10780 and the other two (CMW10781, CMW10779) isolates. This could not be confirmed for sequence data of the TEF-1 $\alpha$ gene region because these cultures (CMW10779, CWM10780) are dead. 


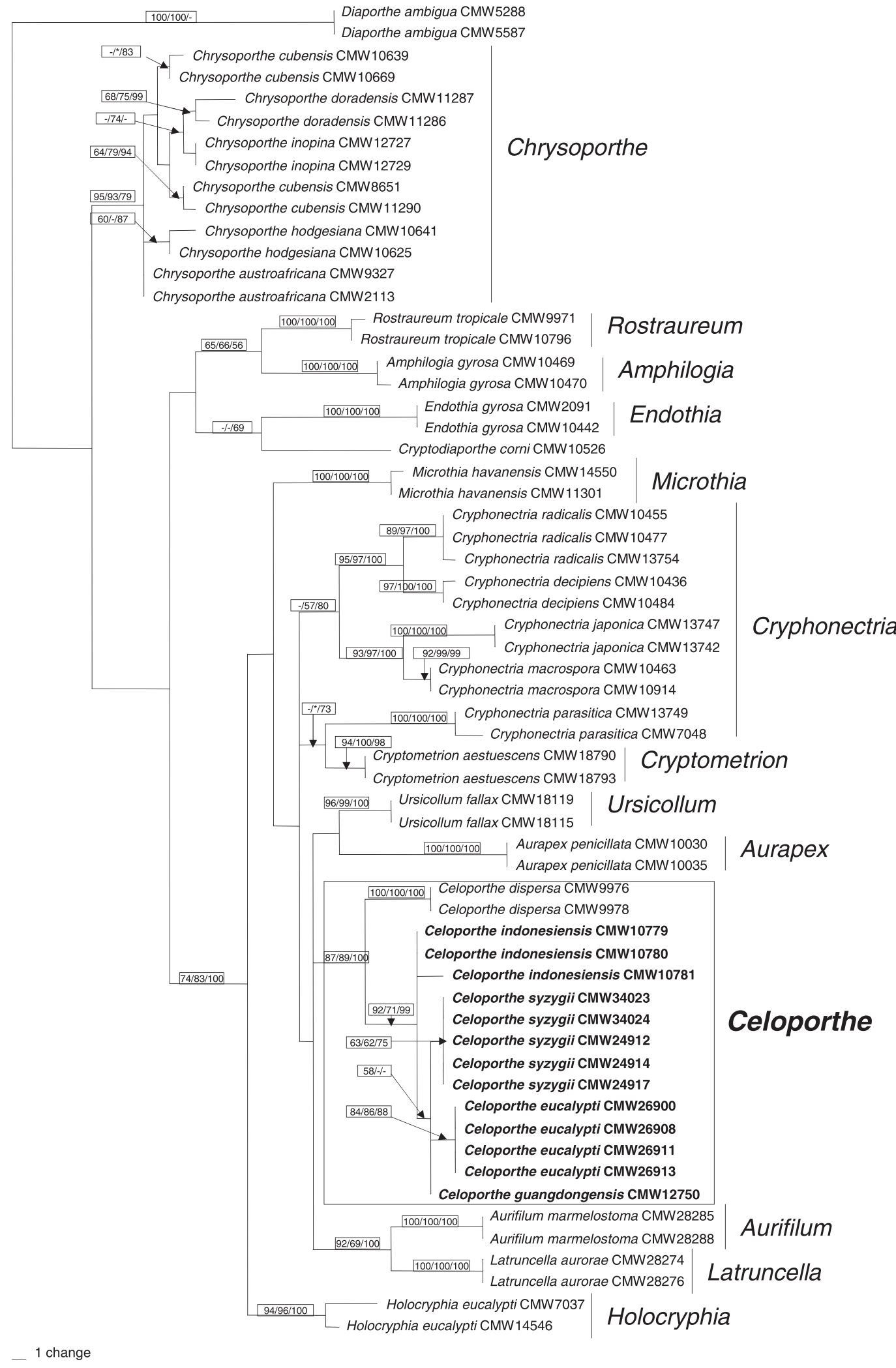

FIG. 3. Cladogram based on maximum parsimony (MP) analysis of a combined DNA sequence dataset of gene regions of the the partial exon 4, exon 5, partial exon 6 and partial exon 7 of the BTgenes, and the 5.8SrRNA gene region. Bootstrap values $>50 \%$ for MP and maximum likelihood (ML), and posterior probabilities $>70 \%$ obtained from Bayesian anlyses are presented above branches as follows: MP/ML/Bayesian. Bootstrap values lower than $50 \%$, posterior probabilities lower than $70 \%$ are marked with *, and analysis value absent is marked with - . Two isolates of Diaporthe ambigua (CMW5587, CMW5288) represent the outgroup. 


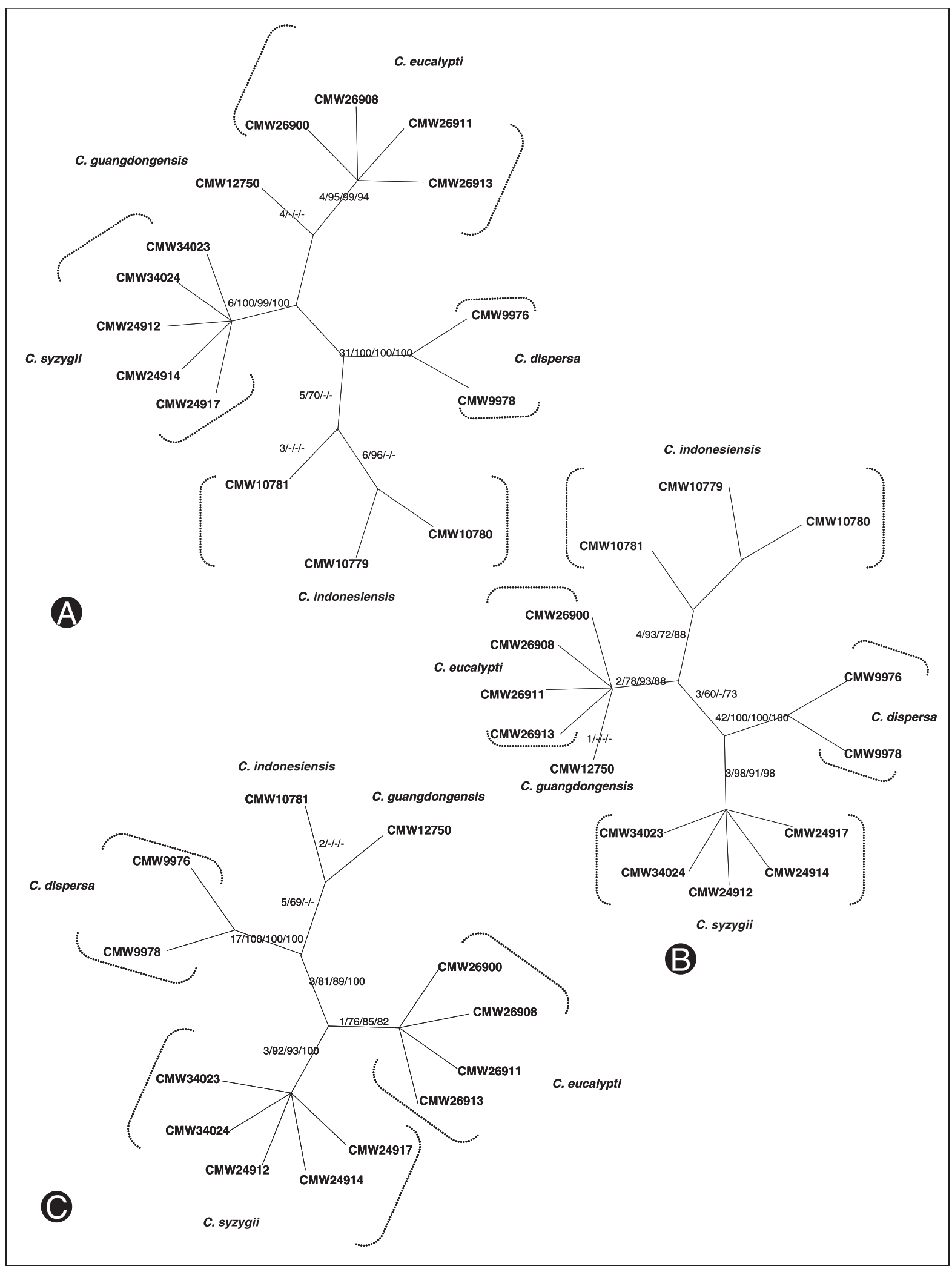

FIG. 4. Unrooted phylogenetic tree obtained with parsimony from DNA sequence datasets of three gene regions. A. BT gene region (BT1 and BT2). B. ITS (ITS1, ITS2 and 5.8S rRNA) region. C. TEF-1 $\alpha$ gene region. Branch length (BL), bootstrap values $>50 \%$ for MP and Maximum likelihood (ML), and posterior probabilities $>70 \%$ obtained from Bayesian anlyses are presented above branches as follows: BL/MP/ML/Bayesian. Bootstrap values lower than 50\%, posterior probabilities lower than $70 \%$ are marked with *, and analysis value absent is marked with - . 
TABLE III. Summary of polymorphic nucleotides found within the $B T$ ( 1 and 2), ITS and the partial $T E F-1 \alpha$ gene regions generated for the phylogenetic groups of Celoporthe syzygii, C. eucalypti, C. guangdongensis and C. indonesiensis

\begin{tabular}{|c|c|c|c|c|c|c|c|c|c|c|c|c|c|c|c|c|c|c|c|}
\hline \multirow[b]{2}{*}{ Species } & \multirow{2}{*}{$\begin{array}{l}\text { Isolate } \\
\text { number }\end{array}$} & \multicolumn{8}{|c|}{$B T 1^{a}$} & \multicolumn{10}{|c|}{$B T 2$} \\
\hline & & $71^{\mathrm{b}}$ & 119 & 141 & 188 & 189 & 192 & 194 & 202 & 24 & 223 & 233 & 234 & 235 & 236 & 237 & 238 & 241 & 327 \\
\hline \multirow[t]{5}{*}{ C. syzygii } & CMW34023 & C & G & $\mathbf{T}^{\mathrm{c}}$ & $\mathrm{C}$ & $\mathrm{T}$ & $\mathrm{C}$ & $\mathrm{C}$ & $\mathbf{A}$ & $\mathrm{C}$ & $\mathbf{A}$ & $\mathrm{C}$ & $\mathrm{C}$ & - & - & $\mathrm{C}$ & $\mathrm{C}$ & $\mathbf{G}$ & $\mathbf{A}$ \\
\hline & CMW34024 & C & G & $\mathbf{T}$ & C & $\mathrm{T}$ & $\mathrm{C}$ & $\mathrm{C}$ & $\mathbf{A}$ & $\mathrm{C}$ & $\mathbf{A}$ & $\mathrm{C}$ & $\mathrm{C}$ & - & - & $\mathrm{C}$ & C & G & $\mathbf{A}$ \\
\hline & CMW24912 & C & G & $\mathbf{T}$ & C & $\mathrm{T}$ & $\mathrm{C}$ & $\mathrm{C}$ & $\mathbf{A}$ & $\mathrm{C}$ & $\mathbf{A}$ & $\mathrm{C}$ & $\mathrm{C}$ & - & - & $\mathrm{C}$ & C & G & $\mathbf{A}$ \\
\hline & CMW24914 & $\mathrm{C}$ & G & $\mathbf{T}$ & C & $\mathrm{T}$ & $\mathrm{C}$ & $\mathrm{C}$ & $\mathbf{A}$ & $\mathrm{C}$ & $\mathbf{A}$ & $\mathrm{C}$ & $\mathrm{C}$ & - & - & $\mathrm{C}$ & $\mathrm{C}$ & G & $\mathbf{A}$ \\
\hline & CMW24917 & $\mathrm{C}$ & G & $\mathbf{T}$ & $\mathrm{C}$ & $\mathrm{T}$ & $\mathrm{C}$ & $\mathrm{C}$ & A & $\mathrm{C}$ & A & $\mathrm{C}$ & $\mathrm{C}$ & - & - & C & $\mathrm{C}$ & G & A \\
\hline \multirow[t]{4}{*}{ C. eucalypti } & CMW26900 & $\mathrm{C}$ & A & C & $\mathrm{C}$ & $\mathrm{T}$ & $\mathbf{T}$ & $\mathrm{C}$ & $\mathrm{C}$ & $\mathbf{T}$ & $\mathrm{C}$ & $\mathrm{C}$ & $\mathrm{T}$ & - & - & - & $\mathrm{C}$ & $\mathrm{C}$ & $\mathrm{C}$ \\
\hline & CMW26908 & C & $\mathbf{A}$ & $\mathrm{C}$ & $\mathrm{C}$ & $\mathrm{T}$ & $\mathbf{T}$ & $\mathrm{C}$ & $\mathrm{C}$ & $\mathbf{T}$ & $\mathrm{C}$ & $\mathrm{C}$ & $\mathrm{T}$ & - & - & - & $\mathrm{C}$ & $\mathrm{C}$ & $\mathrm{C}$ \\
\hline & CMW26911 & $\mathrm{C}$ & $\mathbf{A}$ & C & C & $\mathrm{T}$ & $\mathbf{T}$ & $\mathrm{C}$ & C & $\mathbf{T}$ & $\mathrm{C}$ & $\mathrm{C}$ & $\mathrm{T}$ & - & & - & C & C & C \\
\hline & CMW26913 & $\mathrm{C}$ & A & $\mathrm{C}$ & $\mathrm{C}$ & $\mathrm{T}$ & $\mathbf{T}$ & $\mathrm{C}$ & $\mathrm{C}$ & $\mathbf{T}$ & $\mathrm{C}$ & $\mathrm{C}$ & $\mathrm{T}$ & - & - & - & $\mathrm{C}$ & $\mathrm{C}$ & $\mathrm{C}$ \\
\hline C. guangdongensis & CMW12750 & $\mathbf{T}$ & $\mathrm{G}$ & $\mathrm{C}$ & $\mathbf{T}$ & C & $\mathrm{C}$ & $\mathrm{T}$ & $\mathrm{C}$ & $\mathrm{C}$ & $\mathrm{C}$ & - & - & - & - & - & $\mathrm{C}$ & $\mathrm{C}$ & $\mathrm{C}$ \\
\hline \multirow[t]{3}{*}{ C. indonesiensis } & CMW10779 & $\mathrm{C}$ & G & C & C & $\mathrm{T}$ & $\mathrm{C}$ & $\mathrm{C}$ & $\mathrm{C}$ & C & C & $\mathrm{C}$ & $\mathrm{C}$ & $\mathbf{T}$ & $\mathbf{T}$ & $\mathrm{C}$ & $\mathbf{T}$ & C & C \\
\hline & CMW10780 & C & G & C & C & $\mathrm{T}$ & $\mathrm{C}$ & $\mathrm{C}$ & C & C & C & $\mathrm{C}$ & $\mathrm{C}$ & $\mathbf{T}$ & $\mathbf{T}$ & $\mathrm{C}$ & $\mathbf{T}$ & C & C \\
\hline & CMW10781 & $\mathrm{C}$ & G & $\mathrm{C}$ & C & $\mathrm{T}$ & $\mathrm{C}$ & $\mathrm{C}$ & $\mathrm{C}$ & $\mathrm{C}$ & $\mathrm{C}$ & $\mathrm{C}$ & $\mathrm{C}$ & $\mathbf{T}$ & $\mathrm{T}$ & C & $\mathbf{T}$ & $\mathrm{C}$ & C \\
\hline
\end{tabular}

\footnotetext{
${ }^{a}$ Polymorphic nucleotides occurring only in all isolates are shown, not alleles that partially occur in individuals per phylogenetic group.

${ }^{\mathrm{b}}$ Numerical positions of the nucleotides in the DNA sequence alignments are indicated; numerical positions for the exon of BT and 5.8S rRNA region are shaded.

${ }^{\mathrm{c}}$ Fixed polymorphisms for each group are shaded and in boldface, those fixed but shared between two groups are shaded only.
}

Morphology._-For the morphological examination of material linked the various phylogenetic groups arising from DNA sequence comparisons fruiting bodies of the teleomorph and anamorph states from natural infections were available only for the $S$. cumini isolates from southern China. The fungus on $S$. cumini trees in China was characterized by fruiting structures (FIG. 5) that are morphologically similar to those of $C$. dispersa (Nakabonge et al. 2006a). Both of their teleomorph states were characterized by short, extending, orange to umber, cylindrical perithecical necks (FIG. 5A), semi-immersed stromata (FIG. 5B) and hyaline ascospores with one median septum (FIG. 5G). For the anamorph conidiomata were pulvinate to conical without a prominent neck (FIG. 5H-J), orange when young (FIG. 5H) and fuscous-black when mature. Their conidiomatal base tissue was prosenchymatous (FIG. 5L), and paraphyses or cylindrical sterile cells were present (FIG. 5M). Cultures were fluffy with uneven margins and white when young. A number of differences between $C$. dispers $a$ and the specimens from $S$. cumini were visible. Asci of the fungus from $S$. cumini (av. $34.0 \times 6.0 \mu \mathrm{m}$ ) were longer than those of $C$. dispersa (av. $26.5 \times 6.3 \mu \mathrm{m}$ ). The conidiomatal locules in the $S$. cumini specimens were multilocular, seldom unilocular, while the structures of $C$. dispersa were unilocular, seldom multilocular. The conidia of the $S$. cumini specimens (av. $3.0 \times 1.2 \mu \mathrm{m})$ were smaller than those of $C$. dispersa (av. $3.5 \times 1.5 \mu \mathrm{m}$ ). Cultures of the fungus from S. cumini turned yellow-white to sulfur yellow with sienna/umber patches, while those of $C$. dispersa turned umber to hazel to chestnut with gray patches (Nakabonge et al. 2006a).

Due to the unavailibility of naturally infected tissue representing all four clades from Asia, fruiting structures produced on inoculated branch sections of $S$. cordatum and the E. grandis clone after 6 mo were used to determine morphological differences among the fungi in the clades. For the branch sections where both ends were coated with melted paraffin abundant anamorph structures covered the surface of the bark (FIG. 1C, D). For the branch sections where only the top ends were coated substantially fewer anamorph structures were produced. No teleomorph structures were produced on any of the inoculated branch sections.

Fruiting structures produced on the inoculated branch stubs were similar to those on naturally infected tissue, except for some variations in the shape, size and position of conidiomata (FIGS. 5, 6). For isolates in the same phylogenetic groups fruiting structures on the inoculated $S$. cordatum and $E$. grandis branch sections were similar in terms of conidiomatal position, shape, color and tissue tape making up the conidiomata, structure of conidiomatal locules, as well as shape and size of conidiophores, conidiogenous cells, paraphyses and conidia. Only the conidiomata on $S$. cordatum were larger than 


\begin{tabular}{|c|c|c|c|c|c|c|c|c|c|c|c|c|c|c|c|c|c|c|c|c|c|c|c|c|c|c|c|}
\hline \multicolumn{15}{|c|}{ ITS } & \multicolumn{13}{|c|}{$T E F-1 \alpha$} \\
\hline 40 & 82 & 84 & 85 & 92 & 93 & 97 & 100 & 118 & 132 & 180 & 181 & 211 & 212 & 489 & 35 & 47 & 48 & 76 & 128 & 129 & 138 & 214 & 215 & 230 & 234 & 240 & 249 \\
\hline C & $\mathrm{T}$ & - & - & $\mathbf{T}$ & C & $\mathbf{T}$ & C & $\mathrm{C}$ & - & - & - & - & A & - & C & $\mathbf{T}$ & $\mathbf{T}$ & A & $\mathrm{T}$ & $\mathrm{T}$ & A & - & - & A & G & $\mathrm{T}$ & $\mathrm{T}$ \\
\hline C & $\mathrm{T}$ & - & - & $\mathbf{T}$ & C & $\mathbf{T}$ & C & C & - & - & - & - & A & - & C & $\mathbf{T}$ & $\mathbf{T}$ & A & $\mathrm{T}$ & $\mathrm{T}$ & $\mathrm{A}$ & - & - & $\mathrm{A}$ & G & $\mathrm{T}$ & $\mathrm{T}$ \\
\hline C & $\mathrm{T}$ & - & - & $\mathbf{T}$ & C & $\mathbf{T}$ & C & $\mathrm{C}$ & - & - & - & - & A & - & $\mathrm{C}$ & $\mathbf{T}$ & $\mathbf{T}$ & A & $\mathrm{T}$ & $\mathrm{T}$ & $\mathrm{A}$ & - & - & A & G & $\mathrm{T}$ & $\mathrm{T}$ \\
\hline C & $\mathrm{T}$ & - & - & $\mathbf{T}$ & C & $\mathbf{T}$ & C & $\mathrm{C}$ & - & - & - & - & A & - & C & $\mathbf{T}$ & $\mathbf{T}$ & A & $\mathrm{T}$ & $\mathrm{T}$ & A & - & - & A & G & $\mathrm{T}$ & $\mathrm{T}$ \\
\hline C & $\mathrm{T}$ & - & - & $\mathbf{T}$ & C & $\mathbf{T}$ & C & C & - & - & - & - & A & - & C & $\mathbf{T}$ & $\mathbf{T}$ & A & $\mathrm{T}$ & $\mathrm{T}$ & $\mathrm{A}$ & - & - & $\mathrm{A}$ & $\mathrm{G}$ & $\mathrm{T}$ & $\mathrm{T}$ \\
\hline $\mathrm{C}$ & $\mathrm{T}$ & - & - & C & $\mathrm{T}$ & C & G & - & $\mathrm{G}$ & $\mathrm{A}$ & - & - & - & - & $\mathbf{T}$ & $\mathrm{G}$ & C & A & $\mathrm{T}$ & $\mathrm{T}$ & $\mathrm{A}$ & - & - & A & $\mathrm{G}$ & $\mathrm{T}$ & $\mathrm{T}$ \\
\hline C & $\mathrm{T}$ & - & - & $\mathrm{C}$ & $\mathrm{T}$ & C & $\mathrm{G}$ & - & $\mathrm{G}$ & $\mathrm{A}$ & - & - & - & - & $\mathbf{T}$ & $\mathrm{G}$ & $\mathrm{C}$ & A & $\mathrm{T}$ & $\mathrm{T}$ & $\mathrm{A}$ & - & - & A & G & $\mathrm{T}$ & $\mathrm{T}$ \\
\hline C & $\mathrm{T}$ & - & - & $\mathrm{C}$ & $\mathrm{T}$ & $\mathrm{C}$ & $\mathrm{G}$ & - & $\mathrm{G}$ & $\mathrm{A}$ & - & - & - & - & $\mathbf{T}$ & $\mathrm{G}$ & $\mathrm{C}$ & A & $\mathrm{T}$ & $\mathrm{T}$ & $\mathrm{A}$ & - & - & A & $\mathrm{G}$ & $\mathrm{T}$ & $\mathrm{T}$ \\
\hline C & $\mathrm{T}$ & - & - & C & $\mathrm{T}$ & $\mathrm{C}$ & $\mathrm{G}$ & - & $\mathrm{G}$ & $\mathrm{A}$ & - & - & - & - & $\mathrm{T}$ & $\mathrm{G}$ & $\mathrm{C}$ & A & $\mathrm{T}$ & $\mathrm{T}$ & A & - & - & A & G & $\mathrm{T}$ & $\mathrm{T}$ \\
\hline C & $\mathrm{T}$ & - & - & $\mathrm{C}$ & $\mathrm{T}$ & C & G & C & $\mathrm{G}$ & A & A & - & - & $\mathbf{T}$ & C & $\mathrm{G}$ & C & A & - & - & C & A & - & G & A & C & C \\
\hline $\mathbf{T}$ & $\mathbf{A}$ & $\mathbf{T}$ & $\mathbf{A}$ & $\mathrm{C}$ & $\mathrm{T}$ & C & G & - & $\mathrm{G}$ & - & - & $\mathbf{A}$ & A & - & & & & & & & & & & & & & \\
\hline $\mathbf{T}$ & $\mathbf{A}$ & $\mathbf{T}$ & $\mathbf{A}$ & C & $\mathrm{T}$ & $\mathrm{C}$ & $\mathrm{G}$ & - & $\mathrm{G}$ & - & - & $\mathbf{A}$ & A & - & & & & & & & & & & & & & \\
\hline $\mathbf{T}$ & A & $\mathbf{T}$ & A & C & $\mathrm{T}$ & C & G & - & $\mathrm{G}$ & - & - & $\mathbf{A}$ & A & - & C & $G$ & C & $G$ & & & C & A & 4 & A & $\mathrm{A}$ & $\mathrm{T}$ & $\mathrm{T}$ \\
\hline
\end{tabular}

those on E. grandis (FIGS. 6-9). Similar differences were observed by Hodges et al. (1986) who inoculated excised branch stubs to produce fruiting structures.

The four Asian phylogenetic clades of Celoporthe could be distinguished from $C$. dispersa based on morphological characteristics observed on the limited naturally infected tissue as well as on the artificially inoculated branch pieces. The conidiomata of $C$. dispers $a$ are usually unilocular (TABLE V) (Nakabonge et al. 2006a), while the conidiomata of isolates in all Asian clades were predominantly multilocular (TABLE V, FigS. 5-9). The paraphyses of $C$. dispersa were shorter than those for all the isolates in the Asian clades (TABLE V). Last, the naturally infected bark from $S$. cumini trees showed that the asci of $C$. dispersa are much shorter than those of the Asian isolates (TABLE V). The four Asian phylogenetic clades of Celoporthe also could be distinguished from C. dispersa based on growth characteristics in culture. The optimal temperature for the growth of $C$. dispersa was $25 \mathrm{C}$ (Nakabonge et al. 2006a), while that for isolates in all of the Asian Celoporthe clades was $30 \mathrm{C}$.

Isolates representing the four Asian clades of Celoporthe could be destinghuished based on several morphological features, including length of conidiophores and especially conidial shape and sizes as well as the length of paraphyses (TABLE V; Fig. 10A, B). Lengths of the paraphyses $(P<0.01$ to $P=0.018)$ differed between isolates for each of the four Asian clades. Except for conidial length between isolates of the two clades from the Chinese Eucalyptus clone and a Eucalyptus species $(P=0.74)$, length of the conidia $(P<0.01)$ was significantly different for isolates representing the four Asian clades (FIG. 10A, B). For example the conidia of isolates in the Indonesian Celoporthe clade were the longest $(P<0.01)$ of all isolates in the four Asian clades while the paraphyses of these isolates were shorter $(P<0.01$ to $P=0.018)$ than those of isolates in the two Chinese Celoporthe clades from Eucalyptus trees (TABLE V; Fig. 10A, B).

\section{TAXONOMY}

Based on phylogenetic analyses, the Asian isolates characterized in this study reside in the genus Celoporthe. These isolates could be divided into four phylogenetic clades, separate from that of the type species, C. dispersa. These clades and C. dispersa also could be distinguished from each other, based on characteristics of the asci, conidiomata, conidiophores, conidia, paraphyses and growth in culture.

TABle IV. Number of unique alleles between Celoporthe syzygii, C. eucalypti, C. guangdongensis and C. indonesiensis

\begin{tabular}{lccc}
\hline \hline BT1/2/ITS/TEF-1 $\alpha^{\mathrm{a}}$ & C. eucalypti & C. guangdongensis & C. indonesiensis \\
\hline C. syzygii & $21(10 / 8 / 3)$ & $31(12 / 9 / 10)$ & $29(9 / 11 / 9)$ \\
C. eucalypti & & $21(9 / 3 / 9)$ & $24(9 / 7 / 8)$ \\
C. guangdongensis & & $26(11 / 10 / 5)$ \\
\hline
\end{tabular}

${ }^{\mathrm{a}}$ The order of the three genes: $B T$, ITS and $T E F-1 \alpha$. 

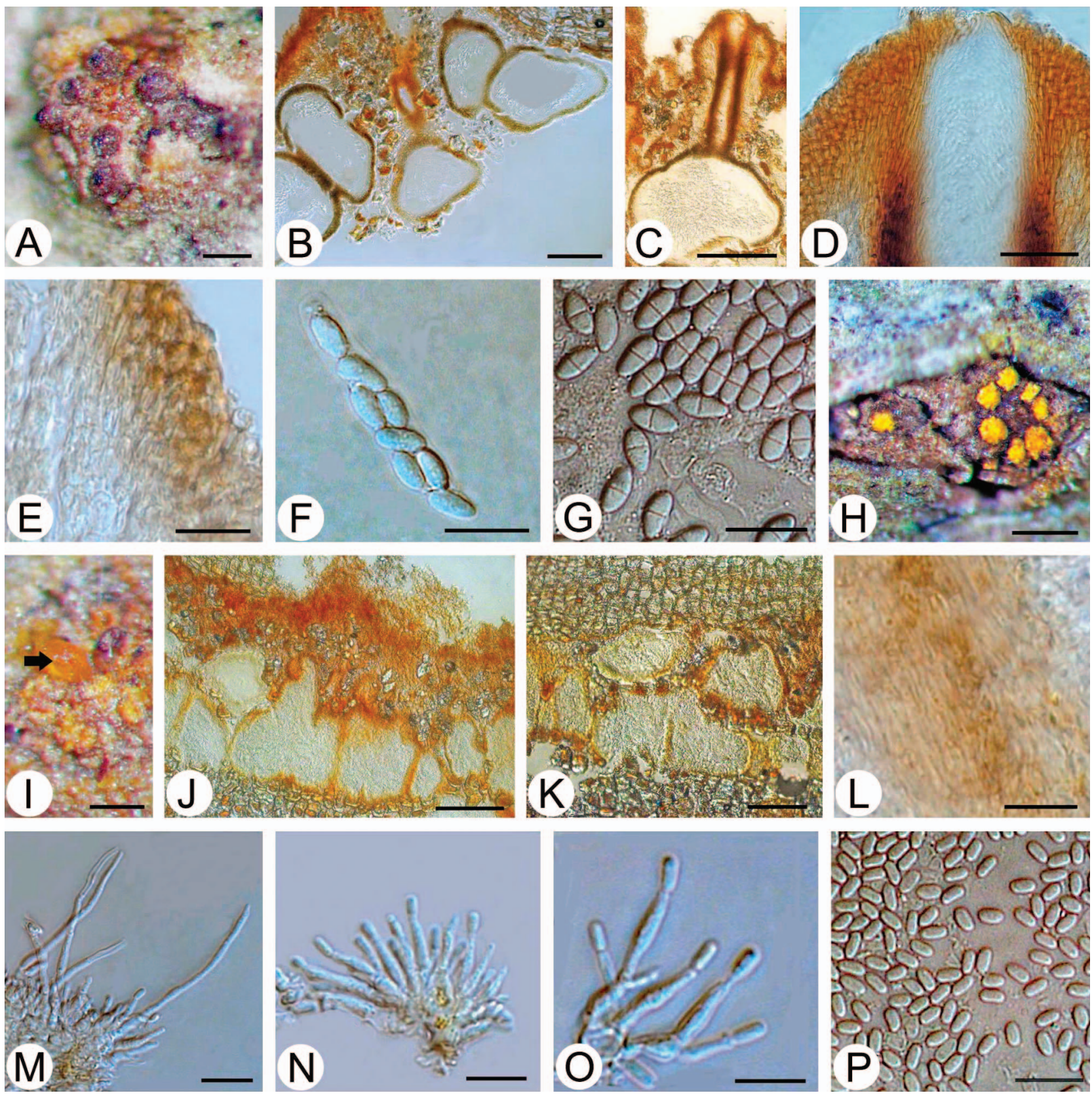

FIG. 5. Fruiting structures of C. syzygii on natural S. cumini trees. A. Ascostroma on bark. B, C. Longitudinal section through ascostroma. D. Perithecial neck tissue. E. Stromatic tissue of ascostroma. F. Ascus with ascospores. G. Ascospores. H, I. Conidomata on the bark (arrow indicate conidial spore mass). J. Longitudinal section through conidioma. K. Latitudinal section through conidioma. L. Stromatic tissue of conidioma. M. Paraphyses. N, O. Conidiophores and conidigenous cells. P. Conidia. Bars: A-C, I-K $=100 \mu \mathrm{m} ; \mathrm{H}=200 \mu \mathrm{m} ; \mathrm{D}=20 \mu \mathrm{m}$; E-G, L-P $=10 \mu \mathrm{m}$.

The Asian isolates therefore represent four distinct species and are described as follows:

Celoporthe syzygii S.F. Chen, Gryzenh., M.J. Wingf. \& X.D. Zhou, sp. nov.

Figs. 5, 6

MycoBank MB519066

Etymology. The name refers to the fact that the species was isolated from Syzygium trees.
Asci fusoidei (29.5-)31.5-36.5(-43) $\times(5-) 5.5-6.5(-7)$ $\mu \mathrm{m}$. Ascosporae oblongo-ellipsoideae (5-)6-7.5(-8.5) $\times$ $2.5-3(-3.5) \mu \mathrm{m}$. Loculi conidiomatum multiloculares raro uniloculares. Conidiophorae (4.5-)6.0-11.0(-16.0) $\mu \mathrm{m}$ longae. Paraphyses usque ad $52 \mu \mathrm{m}$. Conidia oblonga vel cylindrica raro allantoidea, (2.3-)2.8-3.4(-3.8) $\times(1.0-)$ $1.3(-1.6) \mu \mathrm{m}$. A speciebis aliis cladi asiatici Celoporthis $(C$. eucalypti, C. guangdongensis, C. indonesiensis) nucleotidis unice fixis in tribus locis nuclearibus differt: $\beta$-tubulinum- 1 

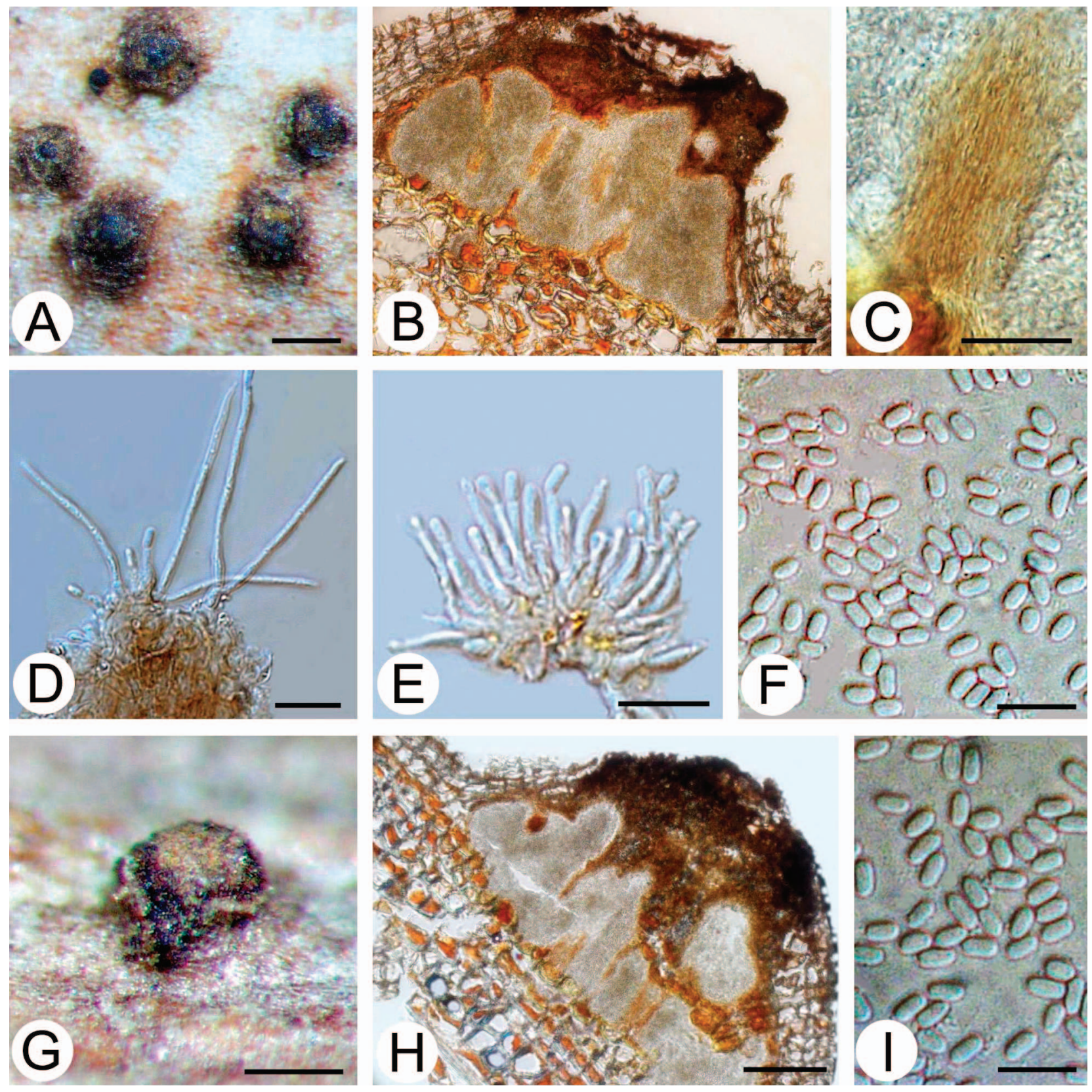

FIG. 6. Fruiting structures of C. syzygii on inoculated branch tissue of S. cordatum (A-F) and an E. grandis clone (G-I). A, G. Conidiomata on the bark. B, H. Longitudinal section through conidioma. C. Stromatic tissue of conidioma. D. Paraphyses. E. Conidiophores and conidigenous cells. F, I. Conidia. Bars: A, B, G, H = $100 \mu \mathrm{m}$; C = $20 \mu \mathrm{m}$; D-F, I = $10 \mu \mathrm{m}$.

sitis 141 (T), $202(\mathrm{~A})$; $\beta$-tubulinum-2 sitis $223(\mathrm{~A}), 241(\mathrm{G})$, 327 (A), loco vulgo "internal transcribed spacer rDNA", dicto (ITS1, 5.8S et ITS2) sitis 92 (T), 93 (C), 97 (T), 100 (C) et 132 (-) et loco vulgo "translation elongation factor 1alpha” dicto sitis $47(\mathrm{~T})$ et $48(\mathrm{~T})$.

Ascostromata on the bark taken from cankers on $S$. cumini trees gregarious, seldom single, immersed or semi-immersed; recognizable by short, extending, umber, cylindrical perithecial necks, occasionally erumpent, limited; orange to umber ascostromatic tissue covering the tops of the perithecial bases; ascostromata 40-240 $\mu \mathrm{m}$ (av. $120 \mu \mathrm{m}$ ) high above the level of bark and 280-580 $\mu \mathrm{m}$ (av. $300 \mu \mathrm{m})$ wide above the surface of the bark (FIG. 5A). Stromatic tissue pseudoparenchymatous at the edges, prosenchymatous in the center (FIG. 5E). Perithecia valsoid, 1-15 per stroma; bases immersed in the bark, black, globose to subglobose, 60-380 $\mu \mathrm{m}$ (av. $170 \mu \mathrm{m}$ ) diam; perithecial wall 10-35 $\mu \mathrm{m}$ (av. $18 \mu \mathrm{m}$ ) thick (FIG. 5B, C); perithecial necks black, emerging through the 

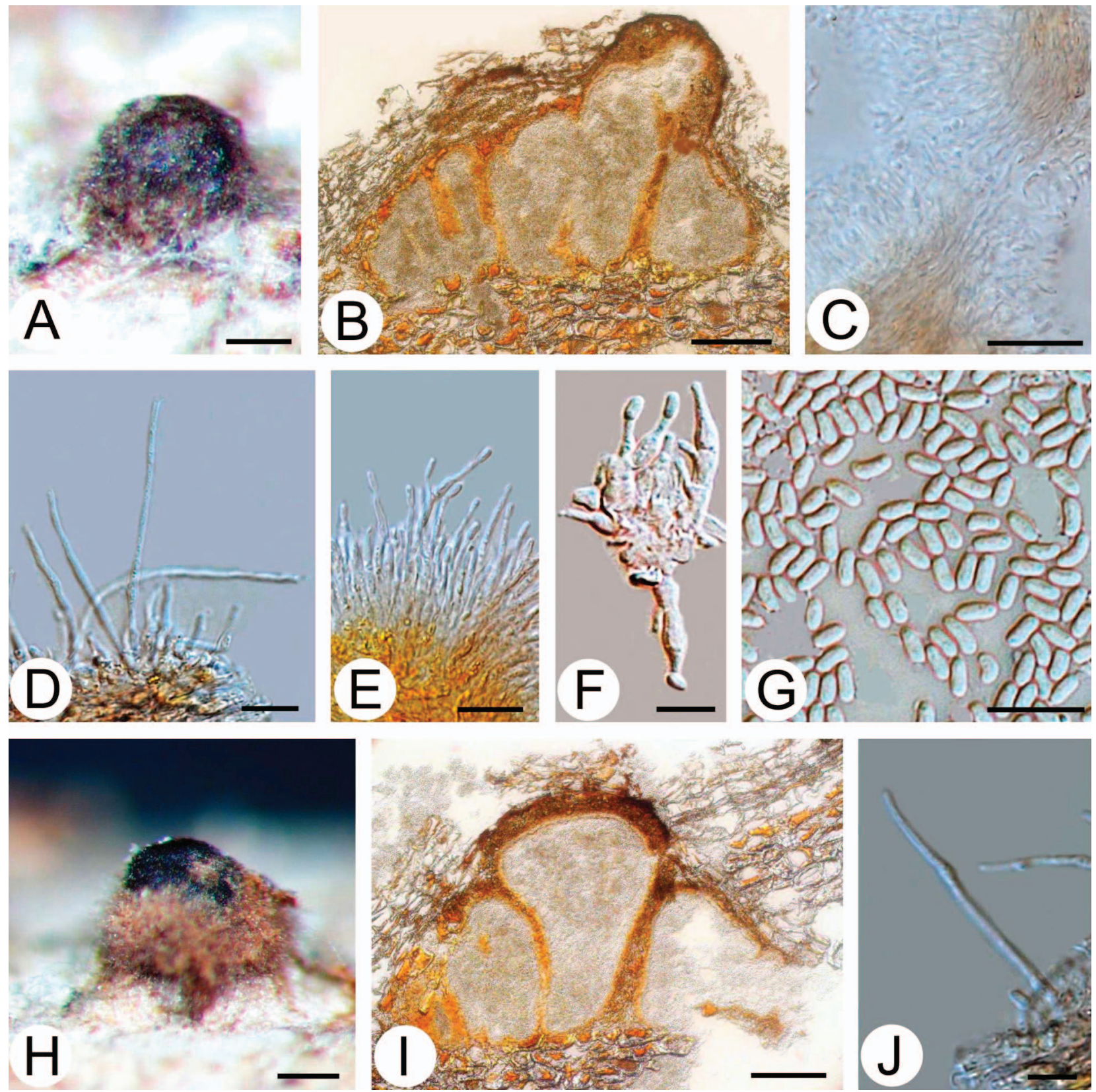

Fig. 7. Fruiting structures of C. eucalypti on inoculated branch tissue of an E. grandis clone (A-G) and S. cordatum (H-J). A, H. Conidiomata on the bark. B, I. Longitudinal section through conidioma. C. Stromatic tissue of conidioma. D, J. Paraphyses. E, F. Conidiophores and conidigenous cells. G. Conidia. Bars: A, B, H, I = $100 \mu \mathrm{m} ; \mathrm{C}=20 \mu \mathrm{m}$; D-G, J = $10 \mu \mathrm{m}$.

stromatal surface, covered in orange to umber stromatic tissue of textura porrecta (FIG. 5D), necks emerge at stromatal surface as black ostioles covered with umber to brown stromatal tissue to form papillae extending up to $40 \mu \mathrm{m}$ long, $40-90 \mu \mathrm{m}$ (av. $55 \mu \mathrm{m}$ ) wide (FIG. 5C). Asci eight-spored, biseriate, unitunicate, free when mature, non-stipitate with a nonamyloid refractive ring, fusoid, (29.5-) 31.5-36.5 (-43) $\times(5-) 5.5-6.5(-7) \mu \mathrm{m}$ (FIG. 5F). Ascospores hyaline, with one median septum, oblong-ellipsoidal, with rounded ends, (5-)6-7.5(-8.5) $\times 2.5-3(-3.5) \mu \mathrm{m}$ (FIG. 5G).

Conidiomata part of ascomata as conidial locules or as solitary structures; immersed to semi-immersed to superficial; pulvinate without necks, occasionally with a neck that is attenuated, orange when young, umber to brown to fuscous-black when mature; conidiomatal base $90-300 \mu \mathrm{m}$ (av. $170 \mu \mathrm{m})$ high above the level of bark and 180-900 $\mu \mathrm{m}$ (av. $420 \mu \mathrm{m}$ ) wide above the surface of the bark (FIG. 5H, I). Conidiomatal locules 

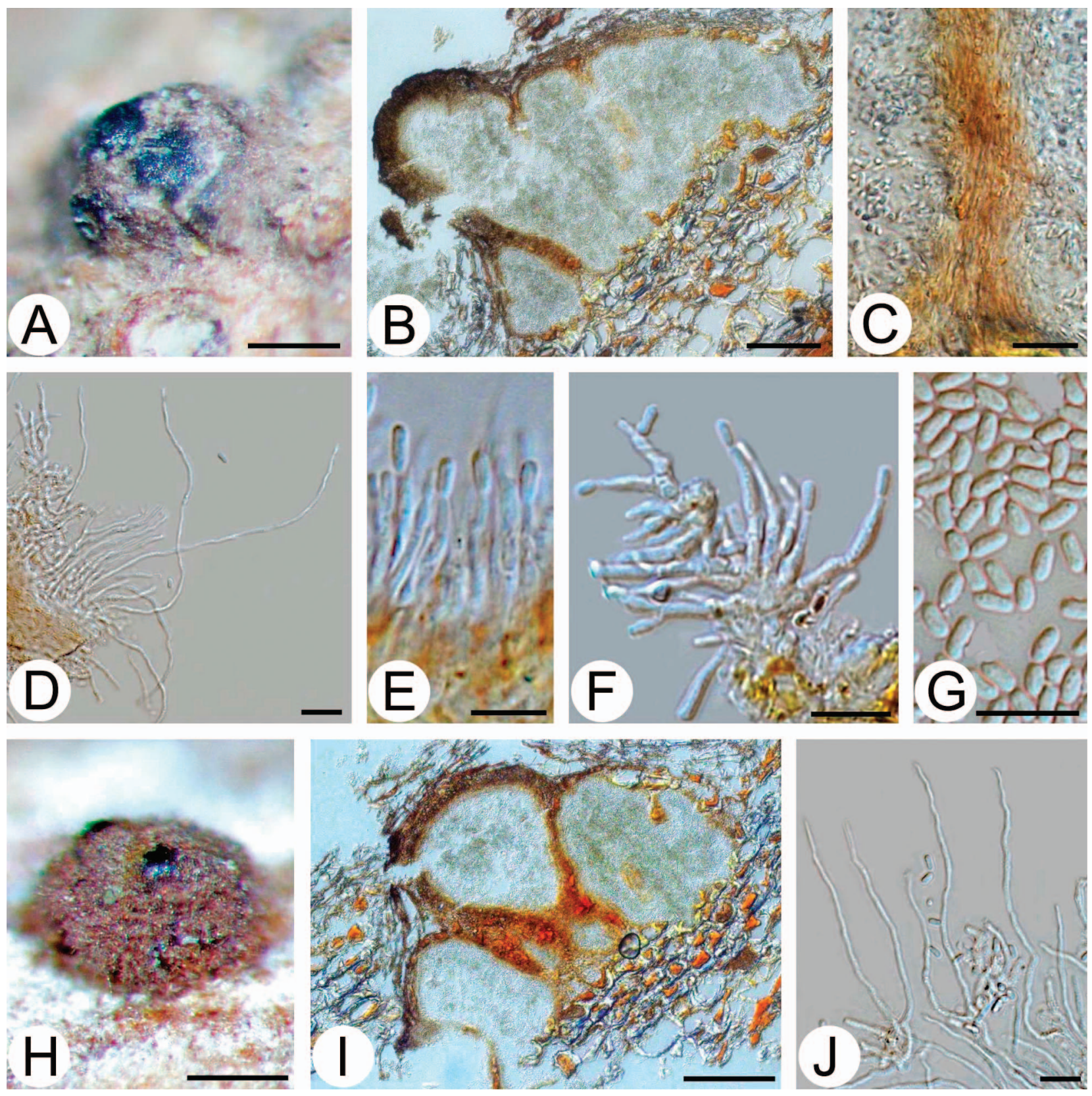

FIG. 8. Fruiting structures of C. guangdongensis on inoculated branch tissue of an E. grandis clone (A-G) and S. cordatum (H-J). A, H. Conidiomata on the bark. B, I. Longitudinal section through conidioma. C. Stromatic tissue of conidioma. D, J. Paraphyses. E, F. Conidiophores and conidigenous cells. G. Conidia. Bars: A, B, H, I = $100 \mu \mathrm{m} ; \mathrm{C}=20 \mu \mathrm{m} ; \mathrm{D}-\mathrm{G}, \mathrm{J}=10 \mu \mathrm{m}$.

multilocular, seldom unilocular, locules 50-650 $\mathrm{m}$ (av. $260 \mu \mathrm{m}$ ) diam (FIG. 5J, K). Stromatic tissue of base prosenchymatous (FIG. 5L). Conidiophores hyaline, branched irregularly at the base or above into cylindrical cells, with or without separating septa, (4.5-) 6.0-9.0(-12.5) $\mu \mathrm{m}$ (av. $8.0 \mu \mathrm{m}$ ) long (FIG. 5N, $\mathrm{O})$. Conidiogenous cells phialidic, cylindrical with or without attenuated apices, 1.0-2.0(-2.5) $\mu \mathrm{m}$ (av. $2.0 \mu \mathrm{m}$ ) wide (FIG. 5N, O). Paraphyses or cylindrical sterile cells occur among conidiophores, up to $44 \mu \mathrm{m}$ long (av. $17 \times 1.5 \mu \mathrm{m})$ (FIg. $5 \mathrm{M})$. Conidia hyaline, non-septate, oblong to cylindrical, occasionally allantoid, pushed through opening at stromatal surface as orange droplets (FIG. 5I), (2.3-)2.8-3.3(-3.7) $\times(1.0-)$ 1.1-1.3(-1.5) $\mu \mathrm{m}($ av. $3.0 \times 1.2 \mu \mathrm{m})$ (FIG. 5P).

No ascostroma were observed on either inoculated $S$. cordatum or E. grandis branch tissue. The inoculated material on both the $S$. cordatum and $E$. grandis branch tissue was similar in morphology to the structures on field-collected $S$. cumini bark 

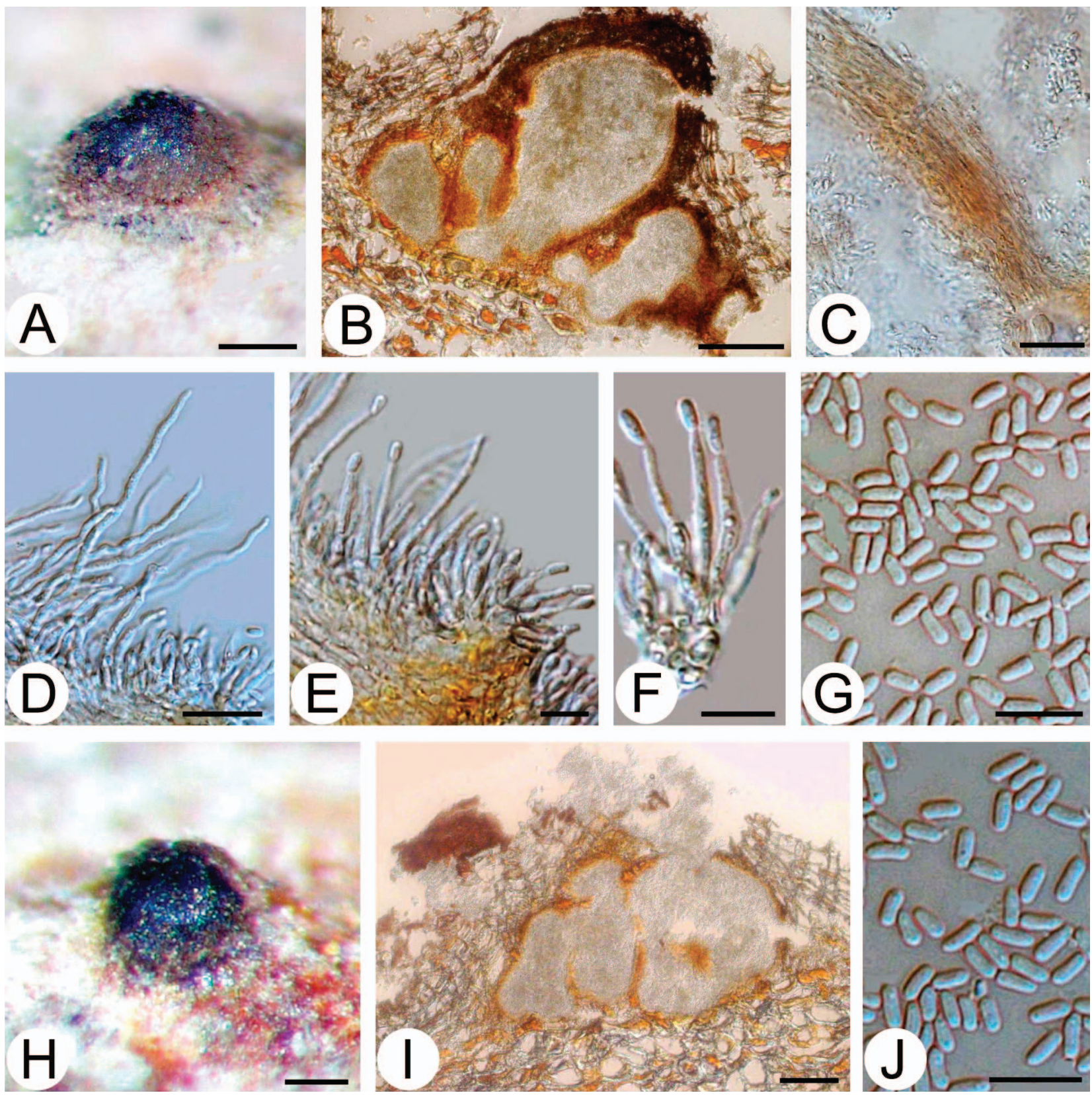

FIG. 9. Fruiting structures of C. indonesiensis on inoculated branch tissue of S. cordatum (A-G) and an E. grandis clone (HJ). A, H. Conidiomata on the bark. B, I. Longitudinal section through conidioma. C. Stromatic tissue of conidioma. D. Paraphyses. E, F. Conidiophores and conidigenous cells. G, J. Conidia. Bars: A, B, H, I = $100 \mu \mathrm{m}$; C $=20 \mu \mathrm{m}$; D-G, J = $10 \mu \mathrm{m}$.

(Figs. 5, 6). However conidiomata on inoculated $S$. cordatum and E. grandis branches were eustromatic, superficial to slightly immersed (FIG. 6B, H); conidiomatal base on $S$. cordatum 100-400 $\mu \mathrm{m}$ (av. $160 \mu \mathrm{m})$ high above the level of bark and 200-700 $\mu \mathrm{m}$ (av. $320 \mu \mathrm{m}$ ) wide above the surface of bark (FIG. 6A); on E. grandis $80-280 \mu \mathrm{m}$ (av. $140 \mu \mathrm{m}$ ) high above the level of bark and 140-620 $\mu \mathrm{m}$ (av. $290 \mu \mathrm{m}$ ) wide above the surface of bark (FIG. 6G). Conidiomatal locules on $S$. cordatum 70-540 $\mu \mathrm{m}$ (av. $250 \mu \mathrm{m}$ ) diam
(FIG. 6B), on E. grandis 40-490 $\mu \mathrm{m}$ (av. $240 \mu \mathrm{m}$ ) diam (FIG. 6H). Paraphyses or cylindrical sterile cells on $S$. cumini branches up to $42 \mu \mathrm{m}$ long (av. $18 \times$ $1.5 \mu \mathrm{m}$ ) (FIG. 6D), on E. grandis branches up to $52 \mu \mathrm{m}$ long (av. $24 \times 1.5 \mu \mathrm{m}$ ).

Celoporthe syzygii differs from other species in the Asian clade of Celoporthe (C. eucalypti, C. guangdongensis, $C$. indonesiensis) by uniquely fixed DNA nucleotides in three nuclear loci, BT1 positions 141 (T) and 202 (A), BT2 positions 223 (A), 241 (G) and 
327 (A); ITS (ITS1, 5.8S, ITS2) positions 92 (T), 93 (C), $97(\mathrm{~T}), 100(\mathrm{C})$ and $132(-)$; TEF- $1 \alpha$ positions 47 (T) and $48(\mathrm{~T})$.

Culture characteristics. On MEA C. syzygii fluffy with an uneven margin, white when young, turning yellow white to sulfur yellow with sienna/umber patches after $10 \mathrm{~d}$. Colony reverse white to yellow-white. Optimal growth temperature $30 \mathrm{C}$, covering the $90 \mathrm{~mm}$ plates after $5 \mathrm{~d}$. No growth at $5 \mathrm{C}$ and $35 \mathrm{C}$; colonies at $10 \mathrm{C}$ reached $31.5 \mathrm{~mm}$ in $30 \mathrm{~d}(6 \mathrm{~mm}$ in $7 \mathrm{~d})$. Asexual fruiting structures occasionally form in primary isolations of the fungus.

Substrate. Bark of Syzygium cumini.

Distribution. China.

Specimens examined. CHINA, GUANGDONG PROVINCE, S. cumini. Sep 2008, S.F. Chen, HOLOTYPE PREM 60462, EX-TYPE culture CMW34023 = CBS127218; PARATYPE PREM 60463, living culture CMW34024; Dec 2006, M.J. Wingfield $\mathcal{E}$ X.D. Zhou, PARATYPE PREM 60464 (isolate CMW24912 = CBS127188, artificial inoculation on South African S. cordatum and E. grandis branch tissue in Apr 2008, S.F. Chen); Dec 2006, M.J. Wingfield E X.D. Zhou, PARATYPE PREM 60465 (isolate CMW24914 = CBS127189, artificial inoculation on South African S. cordatum and E. grandis branch tissue in Apr 2008, S.F. Chen).

Notes. Celoporthe syzygii is morphologically distinguishable from $C$. dispersa by having longer asci (av. 34 $\times 6 \mu \mathrm{m}, \mathrm{L} / \mathrm{W}=5.7)$ than $C$. dispersa (av. $26 \times 6.3 \mu \mathrm{m}$, $\mathrm{L} / \mathrm{W}=4.1$ ). The inoculated conidiomata of $C$. syzygii are more superficial than those of structures formed in nature. The conidia of $C$. syzygii $(2.3-3.8 \mu \mathrm{m})$ are shorter than those of C. guangdongensis $(2.4-4.3 \mu \mathrm{m})$, C. eucalypti $(2.6-4.4 \mu \mathrm{m})$, C. indonesiensis $(3.1-4.7 \mu \mathrm{m})$ and C. dispersa $(2.5-5.5 \mu \mathrm{m})$.

Celoporthe eucalypti S.F. Chen, Gryzenh., M.J. Wingf. \& X.D. Zhou, sp. nov. $\quad$ FIG. 7. MycoBank MB519067

Etymology. Name refers to Eucalyptus, the host from which this fungus first was collected.

Loculi conidiomatum multiloculares raro uniloculares. Conidiophorae (4.5-)9.0-14.0(-25.0) $\mu \mathrm{m}$ longae. Paraphyses usque ad $68 \mu \mathrm{m}$. Conidia $(2.6-) 3.1-3.8(-4.4) \times(1.1-)$ 1.4-1.6(-1.8) $\mu \mathrm{m}$. A speciebis aliis cladi asiatici Celoporthis (C. syzygii, C. guangdongensis, C. indonesiensis) nucleotidis unice fixis in duobus locis nuclearibus differt: $\beta$-tubulinum1 sitis $119(\mathrm{~T})$ et $192(\mathrm{~T}), \beta$-tubulinum-2 sito $24(\mathrm{~T})$, et loco vulgo "translation elongation factor 1-alpha" dicto sito $35(\mathrm{~T})$.

No ascostromata were observed on either the fieldcollected Eucalyptus bark or on inoculated $S$. cordatum and E. grandis branch tissue. Both on $S$. cordatum and $E$. grandis the conidiomata on inoculated branch tissue were eustromatic, superficial to slightly immersed, pulvinate without necks, sometimes conical, orange to umber when young, fuscous- black when mature (FIG. 7A, H). Stromatic tissue of base prosenchymatous (FIG. 7C). However the conidiomatal base on $S$. cordatum 120-600 $\mu \mathrm{m}$ (av. $260 \mu \mathrm{m})$ high above the level of bark and 150$700 \mu \mathrm{m}$ (av. $400 \mu \mathrm{m}$ ) wide above the surface of the bark (Fig. 7H), on E. grandis 100-410 $\mu \mathrm{m}$ (av. $210 \mu \mathrm{m})$ high above the level of bark and 140-650 $\mu \mathrm{m}$ (av. $340 \mu \mathrm{m}$ ) wide above the surface of the bark (FIG. 7A). Conidiomatal locules multilocular, seldom unilocular, locules on S. cordatum 50-510 $\mu \mathrm{m}$ (av. $240 \mu \mathrm{m}$ ) diam (FIG. 7I), locules on E. grandis 35-580 $\mu \mathrm{m}$ (av. $260 \mu \mathrm{m}$ ) diam (FIG. 7B). Conidiophores hyaline, branched irregularly at the base or above into cylindrical cells, with or without separating septa, on S. cordatum (5.5-)9.5-13.5(-22.5) $\mu \mathrm{m}$ (av. $12.0 \mu \mathrm{m})$ long (FIG. 7F), on E. grandis (4.5-)9.0-14.0(-25.0) $\mu \mathrm{m}$ (av. $12 \mu \mathrm{m})$ long (FIG. 7E). Conidiogenous cells phialidic (FIG. 7F), cylindrical with or without attenuated apices, on $S$. cordatum 1.5-2.5(-3.0) $\mu \mathrm{m}$ (av. $2.0 \mu \mathrm{m}$ ) wide, on E. grandis 1.5-3.0(-3.5) $\mu \mathrm{m}$ (av. $2.5 \mu \mathrm{m}$ ) wide (FIG. 7E). Paraphyses or cylindrical sterile cells occur among conidiophores, on $S$. cordatum up to $68 \mu \mathrm{m}$ long (av. $44 \times 1.7 \mu \mathrm{m}$ ) (FIG. 7J), on E. grandis up to $62 \mu \mathrm{m}$ long (av. $40 \times$ $1.6 \mu \mathrm{m}$ ) (FIG. 7D). Conidia hyaline, non-septate, oblong to cylindrical, occasionally allantoid, extend through opening at stromatal surface as orange droplets, on S. cordatum (2.6-) 3.2-3.7(-4.1) $\times(1.2-)$ 1.4-1.6 $(-1.8) \mu \mathrm{m}$, (av. $3.5 \times 1.5 \mu \mathrm{m})$, on E. grandis (2.7-) 3.1-3.8(-4.4) × (1.1-) 1.5-1.7(-1.8) $\mu \mathrm{m}$, (av. 3.5 $\times 1.6 \mu \mathrm{m})$ (FIG. $7 \mathrm{G})$.

Celoporthe eucalypti differs from other species in the Asian clade of Celoporthe (C. syzygii, C. guangdongensis, C. indonesiensis) by uniquely fixed DNA nucleotides in two nuclear loci: BT1 positions 119 (A) and $192(\mathrm{~T})$, BT2 position $24(\mathrm{~T})$; TEF-1 $\alpha$ position $35(\mathrm{~T})$.

Culture characteristics. On MEA C. eucalypti fluffy with an uneven margin, white when young, turning pale luteous to luteous after $10 \mathrm{~d}$. Colony reverse sulfur yellow to pale luteous after $10 \mathrm{~d}$. Optimal growth temperature $30 \mathrm{C}$, covering $90 \mathrm{~mm}$ plates after $6 \mathrm{~d}$. No growth at $5 \mathrm{C}$ and $35 \mathrm{C}$, colonies at $10 \mathrm{C}$ reached $16 \mathrm{~mm}$ in $30 \mathrm{~d}(4 \mathrm{~mm}$ in $7 \mathrm{~d})$. Asexual fruiting structures occasionally formed in primary isolations of the fungus.

Substrate. Bark of Eucalyptus clone.

Distribution. China.

Specimens examined. CHINA, GUANGDONG PROVINCE, Eucalyptus clone. Jan 2007, X.D. Zhou E S.F. Chen. HOLOTYPE PREM 60467 (isolate CMW26908, artificial inoculation on South African S. cordatum and E. grandis branch tissue in Apr 2008, S.F. Chen), EX-TYPE culture CMW26908 = CBS127190; PARATYPE PREM 60466 (isolate CMW26900, artificial inoculation on South African $S$. cordatum and E. grandis branch tissue in Apr 2008, S.F. Chen), EX-TYPE culture CMW26900 = CBS127191. 


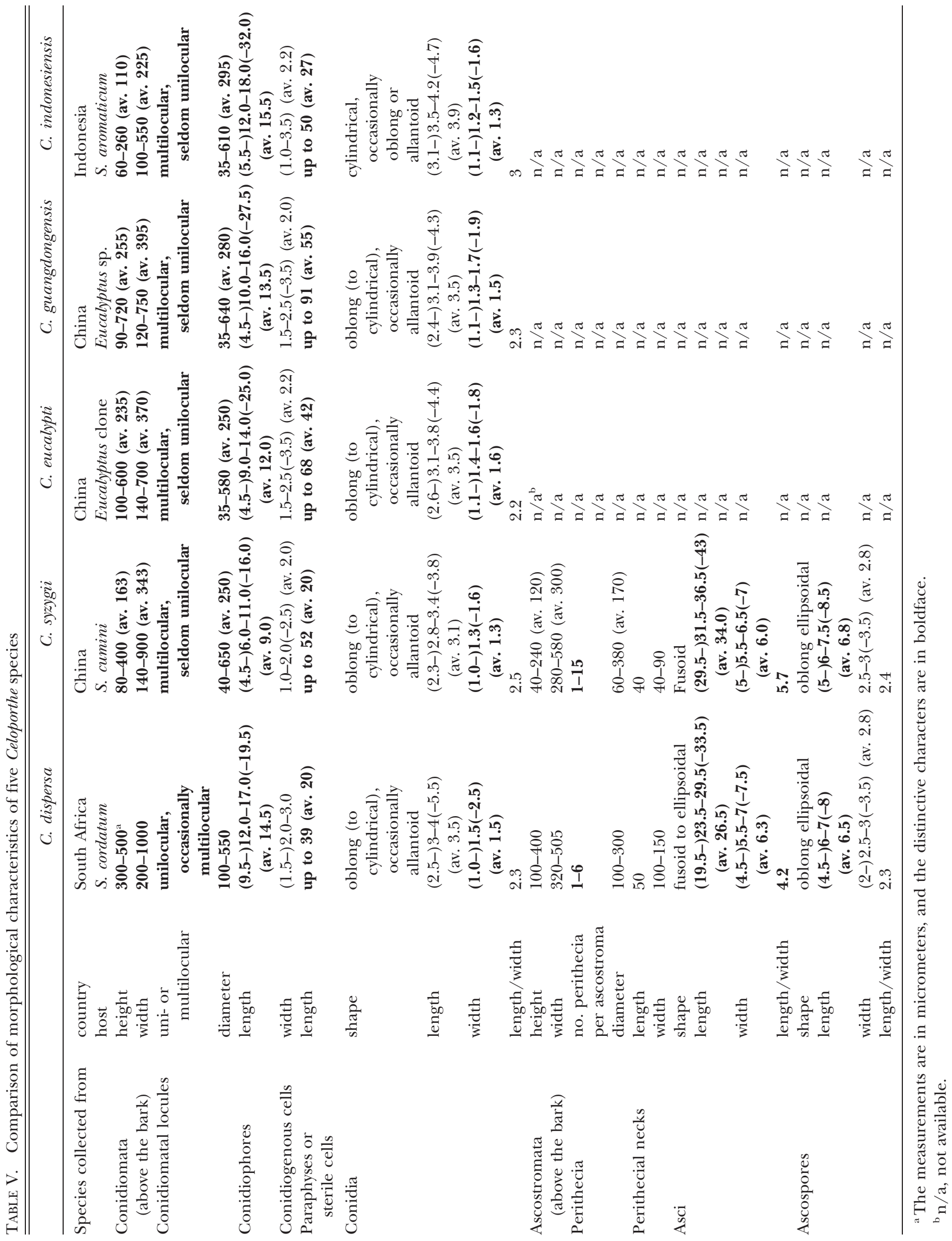



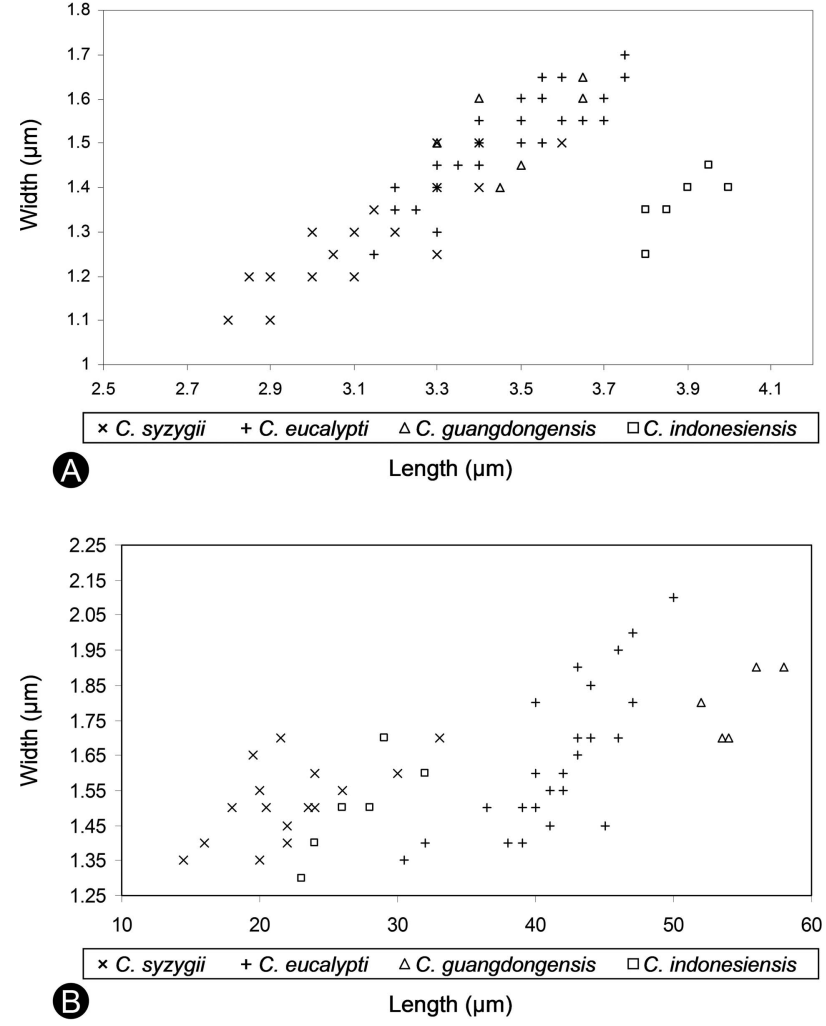

FIG. 10. The average lengths and widths of 10 conidia and 10 paraphyses measured for each of the inoculated $S$. cordatum and E. grandis branch stubs by four species of Celoporthe. A. Conidia. B. Paraphyses.

Notes. Celoporthe eucalypti is morphologically similar to C. guangdongensis but can be distinguished by having shorter paraphyses (up to $68 \mu \mathrm{m}$ ) than $C$. guangdongensis (up to $91 \mu \mathrm{m}$ ). C. eucalypti can be distinguished from $C$. dispersa (paraphyses up to $39 \mu \mathrm{m})$, C. indonesiensis (paraphyses up to $50 \mu \mathrm{m}$ ) and C. syzygii (paraphyses up to $52 \mu \mathrm{m}$ ) by its longer paraphyses. At $10 \mathrm{C}$ on $2 \%$ MEA after $30 \mathrm{~d}$ C. eucalypti grew faster (av. colony diam $=16 \mathrm{~mm}$ ) than $C$. guangdongensis (av. colony diam $=7 \mathrm{~mm}$ ) and $C$. indonesiensis (av. colony diam $=1.5 \mathrm{~mm}$ ) but slower than $C$. syzygii (av. colony diam. $=31.5 \mathrm{~mm}$ ).

Celoporthe guangdongensis S.F. Chen, Gryzenh., M.J. Wingf. \& X.D. Zhou, sp. nov. $\quad$ FIG. 8 MycoBank MB519068

Etymology. Name reflects the GuangDong Province of China where this fungus first was found.

Loculi conidiomatum multiloculares raro uniloculares. Conidiophorae (4.5-) 10.0-16.0(-27.5) $\mu \mathrm{m}$ longae. Paraphyses usque ad $91 \mu \mathrm{m}$. Conidia (2.4-)3.1-3.9(-4.3) $\times(1.1-)$ $1.3-1.7(-1.9) \mu \mathrm{m}$. A speciebis aliis cladi asiatici Celoporthis (C. syzygii, C. guangdongensis, C. indonesiensis) nucleotidis unice fixis in tribus locis nuclearibus differt: $\beta$-tubulinum-1 sitis $71(\mathrm{~T}), 188(\mathrm{~T}), 189(\mathrm{C}), 194(\mathrm{~T})$; $\beta$-tubulinum-2 sitis 233 (-) et $234(-)$; loco vulgo "internal transcribed spacer rDNA" dicto (ITS1, 5.8S et ITS2) sitis 181 (A), 489 (T) et loco vulgo "translation elongation factor 1-alpha" dicto sitis $230(\mathrm{G}), 240(\mathrm{C})$ et $249(\mathrm{C})$.

No ascostromata were observed on Eucalyptus bark collected in the field or on inoculated $S$. cordatum or $E$. grandis branch tissue. Both on S. cordatum and E. grandis the conidiomata on inoculated branch tissue were eustromatic, superficial to slightly immersed, pulvinate without necks, sometimes conical, orange to umber when young, fuscous-black when mature (FIG. 8A, H). Stromatic tissue of base prosenchymatous (FIG. 8C). However the conidiomatal base on $S$. cordatum 90-720 $\mu \mathrm{m}$ (av. $280 \mu \mathrm{m})$ high above the level of bark and 140-750 $\mu \mathrm{m}$ (av. $430 \mu \mathrm{m})$ wide above the surface of the bark (FIG. $8 \mathrm{H}$ ), on E. grandis 110$500 \mu \mathrm{m}($ av. $230 \mu \mathrm{m})$ high above the level of bark and 120-700 $\mu \mathrm{m}$ (av. $360 \mu \mathrm{m}$ ) wide above the surface of the bark (FIG. 8A). Conidiomatal locules multilocular, seldom unilocular, locules on $S$. cordatum 40$590 \mu \mathrm{m}$ (av. $270 \mu \mathrm{m}$ ) diam (FIG. 8I), on E. grandis 35$640 \mu \mathrm{m}$ (av. $290 \mu \mathrm{m}$ ) diam (FIG. 8B). Conidiophores hyaline, branched irregularly at the base or above into cylindrical cells, with or without separating septa, on S. cordatum (4.5-) 10.0-15.0(-24.5) $\mu \mathrm{m}$ (av. $13.0 \mu \mathrm{m})$ long, on E. grandis (5.0-)11.0-16.0(-27.5) $\mu \mathrm{m}$ (av. $14 \mu \mathrm{m}$ ) long (FIG. 8E, F). Conidiogenous cells phialidic, cylindrical with or without attenuated apices, on $S$. cordatum 1.5-2.5 (-3.0) $\mu \mathrm{m}$ (av. $2.0 \mu \mathrm{m})$ wide, on E. grandis 1.5-3.0 (-3.5) $\mu \mathrm{m}$ (av. $2.0 \mu \mathrm{m})$ wide (FIG. 8E, F). Paraphyses or cylindrical sterile cells occur among conidiophores, on $S$. cordatum up to $82 \mu \mathrm{m}$ long (av. $58 \times 1.9 \mu \mathrm{m})$ (FIG. 8J), on E. grandis up to $91 \mu \mathrm{m}$ long (av. $52 \times 1.8 \mu \mathrm{m}$ ) (FIG. 8D). Conidia hyaline, non-septate, oblong to cylindrical, occasionally allantoid, extending through opening at stromatal surface as orange droplets, on S. cordatum (2.4-) 3.3-3.7(-4.0) $\times(1.1-) 1.3-1.6(-1.8) \mu \mathrm{m}, \quad($ av. $3.5 \times$ $1.5 \mu \mathrm{m})$, on E. grandis $(2.5-) 3.1-3.9(-4.3) \times(1.1-)$ 1.4-1.7(-1.9) $\mu \mathrm{m},($ av. $3.5 \times 1.5 \mu \mathrm{m})$ (FIG. 8G).

Celoporthe guangdongensis differs from other species in the Asian clade of Celoporthe (C. syzygii, C. eucalypti, C. indonesiensis) by uniquely fixed DNA nucleotides in three nuclear loci, BT1 positions 71 (T), $188(\mathrm{~T}), 189(\mathrm{C})$ and $194(\mathrm{~T}) ;$ BT2 positions 233 $(-)$ and $234(-)$; ITS (ITS1, 5.8S, ITS2) positions 181 (A) and $489(\mathrm{~T})$; TEF-1 $\alpha$ positions $230(\mathrm{G}), 240(\mathrm{C})$ and $249(\mathrm{C})$.

Culture characteristics. On MEA C. guangdongensis is fluffy with uneven margins, white when young, turning greenish gray to greenish black after $10 \mathrm{~d}$. Colony reverse smoke gray to greenish gray after $10 \mathrm{~d}$. Optimal growth temperature $30 \mathrm{C}$, covering $90 \mathrm{~mm}$ plates after $7 \mathrm{~d}$. No growth at $5 \mathrm{C}$ and $35 \mathrm{C}$, and 
colonies at $10 \mathrm{C}$ reached $7 \mathrm{~mm}$ in $30 \mathrm{~d}$ (nearly no growth in $7 \mathrm{~d}$ ). Asexual fruiting structures occasionally formed in primary isolations of the fungus.

Substrate. Bark of Eucalyptus sp.

Distribution. China.

Specimens examined. CHINA, GUANGDONG PROVINCE, Eucalyptus sp., T.I. Burgess, HOLOTYPE PREM 60468 (isolate CMW12750, artificial inoculation on South African S. cordatum and E. grandis branch tissue in Apr 2008, S.F. Chen), EX-TYPE culture CMW12750 = CBS128341.

Notes. Celoporthe guangdongensis is morphologically different from $C$. dispersa (paraphyses up to $39 \mu \mathrm{m}$ ), $C$. indonesiensis (paraphyses up to $50 \mu \mathrm{m})$, C. syzygii (paraphyses up to $52 \mu \mathrm{m}$ ) and C. eucalypti (paraphyses up to $68 \mu \mathrm{m}$ ) because of its longer paraphyses (up to $91 \mu \mathrm{m})$. This species was described based on the single isolate CMW12750 but supported by strong phylogenetic data and various morphological characteristics different than those of other Celoporthe spp.

Celoporthe indonesiensis S.F. Chen, Gryzenh., M.J. Wingf. \& X.D. Zhou, gen. nov. FIG. 9 MycoBank MB519069

Etymology. Name refers to Indonesia, the country where the fungus first was collected.

Loculi conidiomatum multiloculares raro uniloculares. Conidiophorae (5.5-)12.0-18.0(-32.0) $\mu \mathrm{m}$ longae. Paraphyses usque ad $50 \mu \mathrm{m}$. Conidia (3.1-) 3.5-4.2(-4.7) $\times(1.1-) 1.2-1.5(-1.6) \mu \mathrm{m}$. A speciebis aliis cladi asiatici Celoporthis (C. syzygii, C. guangdongensis, C. eucalypti) nucleotidis unice fixis in tribus locis nuclearibus differt: $\beta$-tubulinum-2 sitis $235(\mathrm{~T})$, 236 (T) 238 (T); loco vulgo "internal transcribed spacer rDNA" dicto (ITS1, 5.8S et ITS2) sitis 40 (T), $82(\mathrm{~A}), 84(\mathrm{~T}), 85$ (T), 211 (A) et loco vulgo "translation elongation factor 1-alpha" dicto sitis 76 (G), $215(\mathrm{C})$.

No ascostromata were observed on the bark of $S$. aromaticum collected in the field or on inoculated $S$. cordatum and $E$. grandis branch tissue. Both on $S$. cordatum and E. grandis, the conidiomata on inoculated branch tissue were eustromatic, superficial to slightly immersed, pulvinate without necks, orange when young, umber to fuscous-black when mature (FIG. 9A, H). Stromatic tissue of base, prosenchymatous (FIG. 9C). However the conidiomatal base on $S$. cordatum 60-260 $\mu \mathrm{m}$ (av. $120 \mu \mathrm{m})$ high above the level of bark and 120-550 $\mu \mathrm{m}$ (av. $260 \mu \mathrm{m}$ ) wide above the surface of the bark (FIG. 9A), on E. grandis 60-250 $\mu \mathrm{m}$ (av. $100 \mu \mathrm{m}$ ) high above the level of bark and 100$470 \mu \mathrm{m}$ (av. $190 \mu \mathrm{m})$ wide above the surface of the bark (FIG. 9H). Conidiomatal locules multilocular, seldom unilocular, locules on $S$. cordatum 50-610 $\mu \mathrm{m}$ (av. $310 \mu \mathrm{m}$ ) diam (FIG. 9B), on E. grandis $35-530 \mu \mathrm{m}$ (av. $280 \mu \mathrm{m}$ ) diam (FIG. 9I). Conidiophores hyaline, branched irregularly at the base or above into cylindrical cells, with or without separating septa, on S. cordatum (6.0-) 14.0-18.0(-29.0) $\mu \mathrm{m}$ (av. $16.0 \mu \mathrm{m})$ long (FIG. 9E, F), on E. grandis (5.5-) 12.0-17.5 $(-32.0) \mu \mathrm{m}$ (av. $15.0 \mu \mathrm{m})$ long. Conidiogenous cells phialidic, cylindrical with or without attenuated apices, on $S$. cordatum 1.5-2.5(-3.5) $\mu \mathrm{m}$ (av. $2.0 \mu \mathrm{m})$ wide (Fig. 9E, F), on E. grandis 1.0-3.0 $\mu \mathrm{m}$ (av. $2.5 \mu \mathrm{m})$ wide. Paraphyses or cylindrical sterile cells occur among conidiophores, on $S$. cordatum up to $48 \mu \mathrm{m}$ long (av. $26 \times 1.5 \mu \mathrm{m})$ (FIG. 9D), on E. grandis up to $50 \mu \mathrm{m}$ long (av. $28 \times 1.5 \mu \mathrm{m})$. Conidia hyaline, non-septate, cylindrical, occasionally oblong or allantoid, extending through opening at stromatal surface as orange droplets, on $S$. cordatum (3.1-) 3.5-4.0 $(-4.6) \times(1.1-) 1.2-1.4(-1.5) \mu \mathrm{m},($ av. $3.8 \times 1.3 \mu \mathrm{m})$ (FIG. 9G), on E. grandis (3.5-)3.7-4.2(-4.7) $\times(1.1-)$ $1.2-1.5(-1.6) \mu \mathrm{m}$, (av. $3.9 \times 1.4 \mu \mathrm{m})$ (FIG. 9J).

Celoporthe indonesiensis differs from other species in the Asian clade of Celoporthe (C. syzygii, C. eucalypti, C. guangdongensis) by uniquely fixed DNA nucleotides in three nuclear loci, BT2 positions 235 (T), 236 (T), and $238(\mathrm{~T})$; ITS (ITS1, 5.8S, ITS2) positions 40 $(\mathrm{T}), 82(\mathrm{~A}), 84(\mathrm{~T}), 85(\mathrm{~A})$ and $211(\mathrm{~A})$; TEF-1 $\alpha$ positions $76(\mathrm{G})$ and $215(\mathrm{C})$.

Culture characteristics. On MEA C. indonesiensis fluffy with an uneven margin, white when young, turning sulfur yellow to pale luteous after $10 \mathrm{~d}$. Colony reverse yellow-white to sulfur yellow after $10 \mathrm{~d}$. Optimal growth temperature $30 \mathrm{C}$, covering the $90 \mathrm{~mm}$ plates after $6 \mathrm{~d}$. No growth at $5 \mathrm{C}$ and $35 \mathrm{C}$, and colonies at $10 \mathrm{C}$ reached $1.5 \mathrm{~mm}$ in $30 \mathrm{~d}$ (nearly no growth in $7 \mathrm{~d}$ ). Asexual fruiting structures occasionally form in primary isolations of the fungus.

Substrate. Bark of Syzygium aromaticum.

Distribution. Indonesia.

Specimens examined. INDONESIA, NORTH SUMATRA, $S$. aromaticum, Sep 1997, M.J. Wingfield, HOLOTYPE PREM 60469 (isolate CMW10781, artificial inoculation on South African S. cordatum and E. grandis branch tissue in Apr 2008, S.F. Chen), EX-TYPE culture CMW10781= CBS115844.

Notes. Celoporthe indonesiensis is morphologically different from C. syzygii (conidia 2.3-3.8 $\mu \mathrm{m}$; paraphyses up to $52 \mu \mathrm{m}$ ), C. eucalypti (conidia 2.6-4.4 $\mu \mathrm{m}$; paraphyses up to $68 \mu \mathrm{m}$ ) and $C$. guangdongensis (conidia 2.4-4.3 $\mu \mathrm{m}$; paraphyses up to $91 \mu \mathrm{m}$ ) because of its longer conidia (3.1-4.7 $\mu \mathrm{m})$ and shorter paraphyses (up to $50 \mu \mathrm{m}$ ). Furthermore its conidia are shorter and paraphyses are longer than those of $C$. dispersa (conidia 2.5-5.5 $\mu \mathrm{m}$; paraphyses up to $39 \mu \mathrm{m}$ ). At $10 \mathrm{C}$ on $2 \%$ MEA after $30 \mathrm{~d}$ C. indonesiensis grew slower (av. colony diam $=1.5 \mathrm{~mm}$ ) than $C$. guangdongensis (av. colony diam $=7 \mathrm{~mm}$ ), C. eucalypti (av. colony diam $=16 \mathrm{~mm}$ ), and C. syzygii (av. colony 
diam $=31.5 \mathrm{~mm}$ ). This species is described based on the phylogenetic placement of three isolates (CMW10779, CMW10780, CMW10781), the morphology of a single isolate (CMW10781) and is supported by strong phylogenetic and morphological differences from other Celoporthe spp.

\section{Dichotomous KeY TO CELOPORTHE SPECIES}

The key is based on characteristics of naturally occurring and artificially induced conidia and paraphyses, as well as growth in culture:

1a. Optimal growth at $25 \mathrm{C}$; conidia longer than $5 \mu \mathrm{m}$; paraphyses shorter than $40 \mu \mathrm{m}$; conidiomata unilocular, occasionally multilocular; Asci* shorter than $35 \mu \mathrm{m} \ldots \ldots \ldots \ldots \ldots$. . dispersa

1b. Optimal growth at $30 \mathrm{C}$; conidia shorter than $5 \mu \mathrm{m}$; paraphyses longer than $45 \mu \mathrm{m}$; conidiomata multilocular, occasionally unilocular; Asci* longer than $40 \mu \mathrm{m} \ldots \ldots \ldots \ldots \ldots \ldots$

2a. Conidia longer than $4.5 \mu \mathrm{m}$, cylindrical, occasionally oblong ............ C. indonesiensis

2b. Conidia shorter than $4.5 \mu \mathrm{m}$, oblong, occasionally

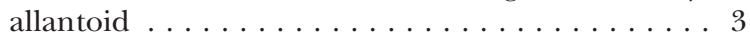

3a. Conidia shorter than $4 \mu \mathrm{m} \quad \ldots \ldots \ldots$. . . . syzygii

3b. Conidia longer than $4 \mu \mathrm{m} \ldots \ldots \ldots \ldots \ldots$

4a. Paraphyses shorter than $70 \mu \mathrm{m}$..... C. eucalypti

4b. Paraphyses longer than $90 \mu \mathrm{m}$... C. guangdongensis

* Teleomorph structures have not been seen for $C$. eucalypti, C. guangdongensis or C. indonesiensis.

\section{SYNOPTIC KEY TO CELOPORTHE SPECIES}

Optimum growth:

a. $25 \mathrm{C:}$ C. dispersa

b. 30 C: C. eucalypti, C. guangdongensis, C. indonesiensis, C. syzygii

Ascus size*:

a. Asci shorter than $35 \mu \mathrm{m}:$ C. dispersa

b. Asci longer than $40 \mu \mathrm{m}$ : C. syzygii

Conidiomatal locules:

a. Unilocular, occasionally multilocular: C. dispersa

b. Multilocular, occasionally unilocular: C. eucalypti, C. guangdongensis, C. indonesiensis, C. syzygii

Conidia morphology (length):

a. Up to $4 \mu \mathrm{m}$ : C. syzygii

b. Up to $4.5 \mu \mathrm{m}$ : C. eucalypti, C. guangdongensis

c. Up to $4.75 \mu \mathrm{m}$ : C. indonesiensis

d. Up to $5.5 \mu \mathrm{m}$ : C. dispersa

Paraphyses morphology (length):

a. Up to $40 \mu \mathrm{m}$ : C. dispersa

b. Up to $50 \mu \mathrm{m}$ : C. indonesiensis

c. Slightly longer than $50 \mu \mathrm{m}$ : C. syzygii

d. Up to $70 \mu \mathrm{m}$ : C. eucalypti

e. Up to $90 \mu \mathrm{m}:$ C. guangdongensis

Conidial morphology:

a. Conidia mostly cylindrical, occasionally oblong or allantoid: C. indonesiensis b. Conidia mostly oblong, occasionally allantoid: $C$. dispersa, C. eucalypti, C. guangdongensis, C. syzygii

* Teleomorph structures have not been seen for $C$. eucalypti, C. guangdongensis or C. indonesiensis.

Pathogenicity tests._Glasshouse trials. The three isolates of C. eucalypti (CMW26900, CMW26908, CMW26911) tested for pathogenicity on Eucalyptus clone TAG-5 in the glasshouse produced lesions within $6 \mathrm{wk}$, while wounds were covered with callus tissue in the case of the control inoculations (FIG. 11). Mean comparison tests showed that the lesion lengths produced by the $C$. eucalypti isolates were significantly longer $(P<0.0001$ to $P=0.0047)$ than those of the controls (FIG. 11). Analyses of variance showed significant differences in susceptibility of the Eucalyptus clone to the fungal isolates $(P=0.0433)$. Of the isolates tested lesions produced by isolate CMW26908 were the longest, differing significantly from isolate CMW26900 and the controls (FIG. 11). All the inoculated fungi were successfully re-isolated from the lesions, while Celoporthe was not isolated from the control inoculations. Based on the glasshouse trial, the most virulent isolate, CMW26908, was chosen for use in field inoculations.

Field trials. Statistically significant differences in lesion lengths on the seven Eucalyptus genotypes were found between the isolates identified as C. eucalypti (CMW26908) and C. guangdongensis (CMW12750), and the control inoculations $(P<0.0001$ to $P=$ 0.0230 ) after $5 \mathrm{wk}$ under field conditions (FIG. 12). Eucalyptus genotypes CEPT-2 and CEPT-6 were the most susceptible to both Celoporthe spp., while genotypes CEPT-3, CEPT-4 and CEPT-5 were relatively

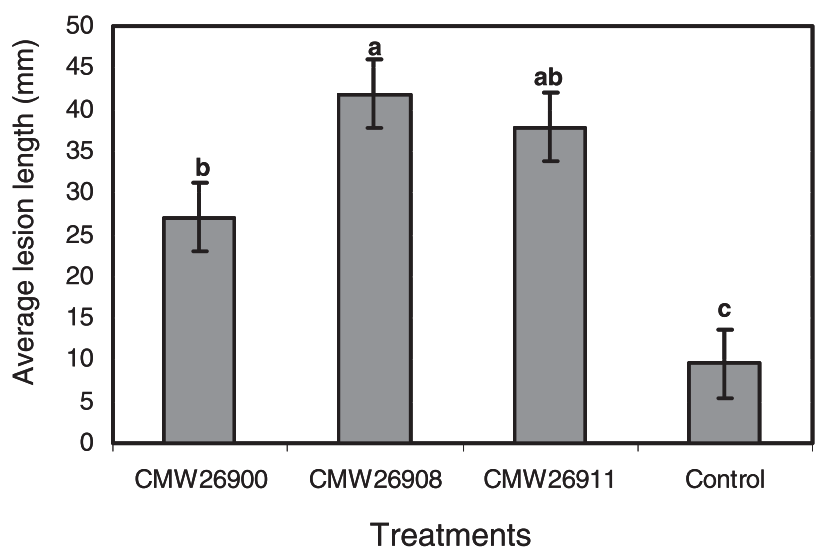

FIG. 11. Histogram showing the average lesion lengths $(\mathrm{mm})$ resulting from inoculations onto $E$. grandis clone (TAG-5) under glasshouse conditions. Three isolates of $C$. eucalypti from Eucalyptus trees in China were used. Bars represent $95 \%$ confidence limits for each treatment. Letters above the bars indicate treatments that statistically were significantly different $(P=0.05)$. 


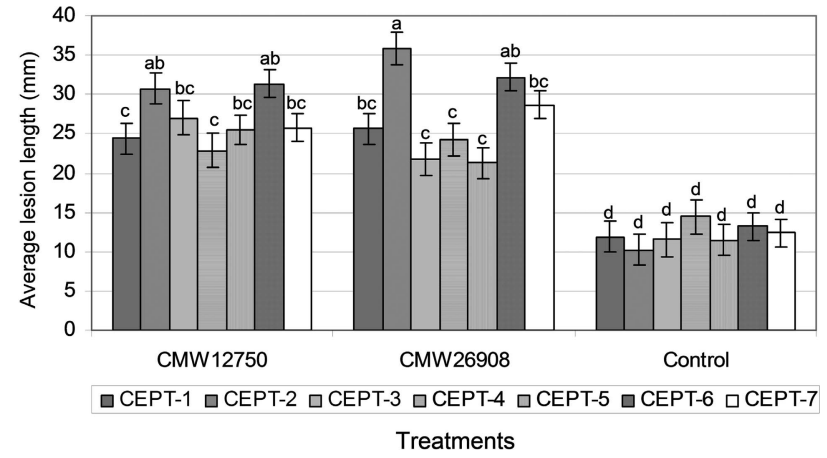

FIG. 12. Histogram showing the average lesion lengths $(\mathrm{mm})$ resulting from inoculations of seven Eucalyptus genotypes with isolate CMW12750 (C. guangdongensis) and isolate CMW26908 (C. eucalypti). Bars represent 95\% confidence limits for each treatment. Different letters above the bars indicate treatments that statistically were significantly different $(P=0.05)$.

tolerant to infection by C. eucalypti and C. guangdongensis (FIG. 12).

The trial, including three C. syzygii isolates (CMW24912, CMW24914, CMW24917), C. eucalypti (CMW26908) and C. guangdongensis (CMW12750) on two Eucalyptus genotypes (CEPT-6, CEPT-7), showed that the Celoporthe isolates produced significantly longer lesions $(P<0.0001$ to $P=0.0380)$ on the two tested Eucalyptus genotypes than the control inoculations that had started to heal through the production of callus tissue (FIG. 13A). Analyses of variance showed significant differences $(P<0.001)$ in susceptibility between the two Eucalyptus genotypes, with CEPT-6 being more susceptible to infection by $C$. guangdongensis (CMW12750) and C. syzygii (CMW24912, CMW24914, CMW24917) than CEPT-7 $(P<0.0001$ to $P=0.0302)$ (FIG. 13A). No statistically significant differences were found between CEPT-6 and CEPT-7 for C. eucalypti (CMW26908) $(P=$ $0.1621)$. No differences were found between the $C$. syzygii isolates and the two Celoporthe spp. that originated from Eucalypts on clone CEPT-6 $(P=$ 0.0676 to $P=1.0000$ ), however on CEPT-7 the Eucalyptus isolates CMW26908 (C. eucalypti) and CMW12750 (C. guangdongensis showed higher virulence on Eucalypts than the C. syzygii isolates.

The three Celoporthe spp. inoculated onto the branches of $S$. cumini produced significantly $(P<$ $0.0001)$ longer lesions than the control inoculations after $6 \mathrm{wk}$ (FIG. 13B). The analyses showed no statistical differences between the two sets of inoculations $(P=0.2421)$ and therefore the data were combined. Analyses of variance for the combined data showed significant differences in susceptibility to the fungal isolates $(P=0.0004)$. For example the $C$.
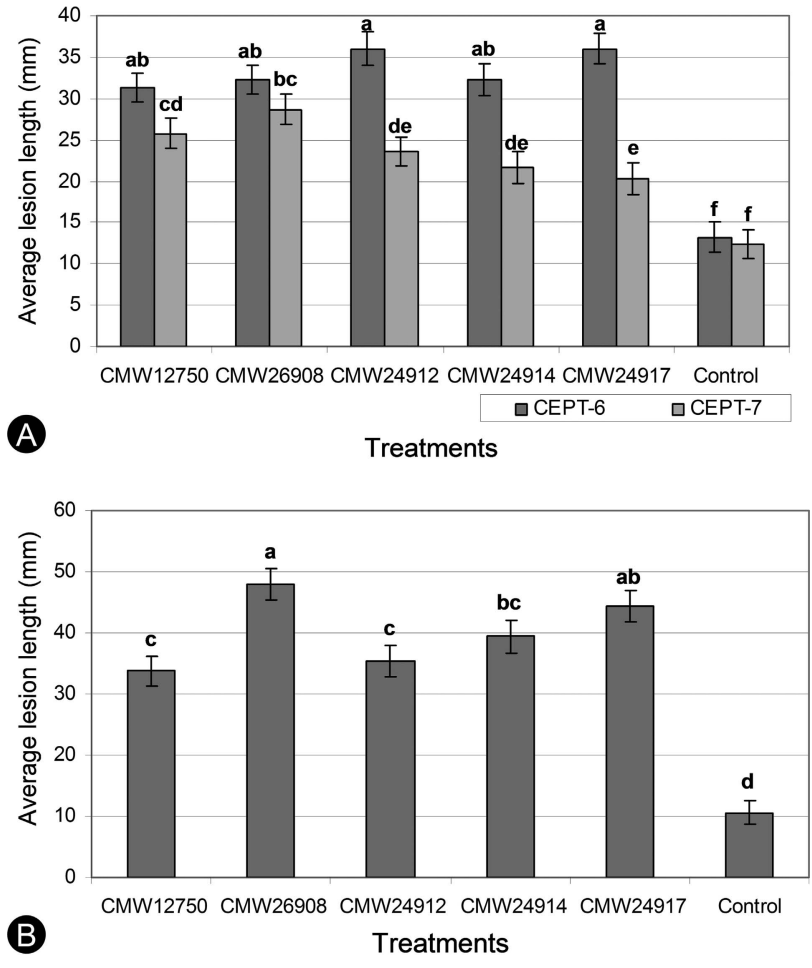

FIG. 13. Histogram showing average lesion lengths $(\mathrm{mm})$ resulting from inoculation of (A). Two Eucalyptus genotypes (CEPT-6, CEPT-7) and (B). S. cumini branches with three isolates (CMW24912, CMW24914, CMW24917) of C. syzygii, one isolate (CMW26908) of C. eucalypti and one isolate (CMW12750) of C. guangdongensis. Bars represent $95 \%$ confidence limits for each treatment. Letters above the bars indicate treatments that statistically were significantly different $(P=0.05)$.

eucalypti isolate (CMW26908) produced significantly $(P=0.0001$ to $P=0.0215)$ longer lesions than the $C$. guangdongensis isolate (CMW12750) and the $C$. syzygii isolates (CMW24912, CMW24914; FIG. 13B).

\section{DISCUSSION}

In this study four previously undescribed species of Celoporthe were found on bark collected from diseased Syzygium and Eucalyptus trees in Asia. C. syzygii was collected from $S$. cumini trees in China, both $C$. eucalypti and C. guangdongensis from non-native Eucalyptus trees in China and C. indonesiensis isolates originated from $S$. aromaticum trees in Indonesia. The identification of these species was supported by phylogenetic analyses and SNP determination as well as morphological characteristics. The species from Eucalyptus in China also were shown to be capable of causing lesions on commercially utilized Eucalyptus genotypes and on branches of S. cumini trees.

In this study anamorph fruiting structures were successfully induced on Eucalyptus and Syzygium 
branch sections for all of the Celoporthe isolates. Differences were observed between the naturally occurring anamorph structures for $C$. syzygii and those formed on the inoculated branch sections, especially relating to the shape and position of conidiomata. However characteristics, such as diameter of conidiomata, sizes of conidiophores, conidigenous cells and conidia in $C$. syzygii, were similar in the artificially induced and naturally occurring fruiting structures and they therefore were useful in distinguishing between the four Asian phylogenetic Celoporthe spp.

Phylogenetic analyses for isolates of Celoporthe suggested clustering of species based on geographic origin and host. Thus the three Chinese Celoporthe spp. were more closely related to each other than to Indonesian $C$. indonesiensis. In contrast the Chinese C. eucalypti and C. guangdongensis from Eucalyptus in China were more closely related to each other than to C. syzygii from Syzygium. Similarly the Celoporthe species formed two major clades, one including $C$. dispersa from Africa and the other including the Asian species described in the present study. Nakabonge et al. (2006a) also suggested clustering of Celoporthe isolates from South Africa, based on host and regions of collection, but they were not able to explain these results due to the limited number of isolates available.

The discovery of the Celoporthe spp. in Asia raises interesting questions regarding the origin of these fungi. Nakabonge et al. (2006a) suggested that $C$. dispersa might have originated from native African Myrtales. Similarly all four Celoporthe spp. that were identified from non-native trees in this study might have originated from native Myrtales in southern or southeastern Asia. This is especially likely due to the species diversity of Celoporthe in Asia. Additional surveys however are necessary to expand the host and geographic ranges of Celoporthe spp. in southeastern Asia and other regions to obtain a better indication of their possible origins.

Research showed that some pathogens in the Cryphonectriaceae may undergo host shifts (Slippers et al. 2005), enabling them to infect tree species other than their native hosts (Wingfield 2003; Gryzenhout et al. 2004, 2006b, 2009, 2010; Heath et al. 2006; Nakabonge et al. 2006a, b; Begoude et al. 2010; Vermeulen et al. 2011). It has been suggested further that species of Chrysoporthe that infect non-native plantation-grown Eucalyptus have originated from native trees in the Myrtales (Gryzenhout et al. 2004; Rodas et al. 2005; Heath et al. 2006; Gryzenhout et al. 2006b, 2009, 2010). A similar host shift could have occurred with $C$. dispersa and the four Celoporthe spp. described in this study. In the present study all four Celoporthe spp. were isolated from non-native trees in
Asia. This includes C. indonesiensis, which was found on planted $S$. aromaticum trees in northern Sumatra, Indonesia, where these trees do not occur naturally. The ability of the four Celoporthe spp. to infect Syzygium trees that are native to southern and southeastern Asia suggests that these fungi could have originated from these or related trees and that they have undergone host shifts to infect Eucalyptus species.

The pathogenicity tests in this study showed that Chinese Celoporthe spp. from S. cumini and Eucalyptus are pathogenic to various Eucalyptus genotypes and $S$. cumini trees. Similar lesion sizes also were produced on both Eucalyptus genotypes and S. cumini trees by Chr. deuterocubensis (Chen et al. 2010), which suggests that Celoporthe spp. might be equally important potential pathogens of Eucalyptus in China. Similar to the results of the screening trials with Chr. deuterocubensis in China (Chen et al. 2010), the inoculations in this study showed that Eucalyptus genotypes differ in susceptibility to infection by Celoporthe spp. These results further imply that it will be possible to select Eucalyptus planting stock with tolerance to infection by these fungi.

Pathogenicity tests showed that cross infectivity between Eucalyptus and Syzygium is possible by the Celoporthe spp. described in thus study. For example the isolates of C. syzygii collected from Syzygium trees were more pathogenetic on the tested Eucalyptus genotype CEPT-6 than isolates of $C$. eucalypti and $C$. guangdongensis from Eucalyptus trees. Likewise the isolate of C. eucalypti collected from an Eucalyptus clone was more pathogenic on Syzygium trees than the isolates of $C$. syzygii collected from Syzygium. Pathogenicity studies with $C$. dispersa have shown that an isolate of this fungus collected from Tibouchina granulosa Cogn.: Britton was more pathogenic on an Eucalyptus clone than on T. granulosa plants (Nakabonge et al. 2006a). The cross infectivity of Celoporthe spp. on different hosts suggests that quarantine regulations should consider these alternative hosts to prevent the pathogens from moving to new areas.

\section{ACKNOWLEDGMENTS}

This study was initiated through the bilateral agreement between South Africa and China, and financially supported through projects 2007DFA31190, 2008B050100014 and 10145624536-400000. We also appreciate the financial and logistical support of the members of Tree Protection Co-operative Programme (TPCP) and Dr Treena I. Burgess (Murdoch University, Australia) for providing some isolates used in this study. We are grateful for the help of Prof Hennie Groeneveld and Dr Mike van der Linde who assisted with the statistical analyses, Dr Hugh Glen who provided the Latin description, Miss Marcele Vermeulen 
for the TEF-1 $\alpha$ sequence data for Celoporthe dispersa, and colleagues of LeiZhou Forestry Bureau, XinTao Mou, GuiXiang Zhao and ChunYan Xie for their valuable assistance in the field.

\section{LITERATURE CITED}

Anagnostakis SL. 1987. Chestnut blight: the classical problem of an introduced pathogen. Mycologia 79: 23-37, doi:10.2307/3807741

- 1992. Chestnuts and the introduction of chestnut blight. Ann Rep N Nut Grow Assoc 83:39-42.

Begoude BAD, Gryzenhout M, Wingfield MJ, Roux J. 2010. Aurifilum, a new fungal genus in the Cryphonectriaceae from Terminalia species in Cameroon. Anton Leeuw Int J G 98:263-278, doi:10.1007/s10482-010-9467-8

Carbone I, Kohn LM. 1999. A method for designing primer sets for speciation studies in filamentous ascomycetes. Mycologia 91:553-556, doi:10.2307/3761358

Castlebury LA, Rossman AY, Jaklitsch WJ, Vasilyeva LN. 2002. A preliminary overview of the Diaporthales based on large subunit nuclear ribosomal DNA sequences. Mycologia 94:1017-1031, doi:10.2307/3761867

Cheewangkoon R, Groenewald JZ, Summerell BA, Hyde KD, To-anun C, Crous PW. 2009. Myrtaceae, a cache of fungal biodiversity. Persoonia 23:55-85.

Chen SF, Gryzenhout M, Roux J, Xie YJ, Wingfield MJ, Zhou XD. 2010. Identification and pathogenicity of Chrysoporthe cubensis on Eucalyptus and Syzygium species in south China. Plant Dis 94:1143-1150, doi:10.1094/ PDIS-94-9-1143

Fairchild D. 1913. The discovery of the chestnut bark disease in China. Science 38:297-299, doi:10.1126/ science.38.974.297

Farris JS, Kallersjo M, Kluge AG, Bult C. 1995. Testing significance of incongruence. Cladistics 10:315-319, doi:10.1111/j.1096-0031.1994.tb00181.x

Felsenstein J. 1985. Confidence intervals on phylogenetics: an approach using bootstrap. Evolution 39:783-791, doi: $10.2307 / 2408678$

Glass NL, Donaldson GC. 1995. Development of primersets designed for use with the PCR to amplify conserved genes from filamentous ascomycetes. Appl Environ Microbiol 61:1323-1330.

Gryzenhout M, Myburg H, van der Merwe NA, Wingfield BD, Wingfield MJ. 2004. Chrysoporthe, a new genus to accommodate Cryphonectria cubensis. Stud Mycol 50: 119-142.

_, ——, Wingfield BD, Wingfield MJ. 2006a. Cryphonectriaceae (Diaporthales), a new family including Cryphonectria, Chrysoporthe, Endothia and allied genera. Mycologia 98:239-249, doi:10.3852/mycologia.98.2.239

- Rodas CA, Menas Portales J, Clegg P, Wingfield BD, Wingfield MJ. 2006b. Novel hosts of the Eucalyptus canker pathogen Chrysoporthe cubensis and a new Chrysoporthe species from Colombia. Mycol Res 110: 833-845, doi:10.1016/j.mycres.2006.02.010

__- Tarigan M, Clegg PA, Wingfield MJ. 2010. Cryptometrion aestuescens gen. sp. nov. (Cryphonectria- ceae) pathogenic to Eucalyptus in Indonesia. Australas Plant Path 39:161-169, doi:10.1071/AP09077

— Wingfield BD, Wingfield MJ. 2009. Taxonomy, phylogeny and ecology of bark-inhabiting and tree pathogenic fungi in the Cryphonectriaceae. St Paul, Minnesota: APS Press. 119 p.

Guindon S, Gascuel O. 2003. A simple, fast and accurate algorithm to estimate large phylogenies by maximum likelihood. Syst Biol 52:696-704, doi:10.1080/ 10635150390235520

Heath R, Gryzenhout M, Roux J, Wingfield MJ. 2006. Discovery of the canker pathogen Chrysoporthe austroafricana on native Syzygium spp. in South Africa. Plant Dis 90:433-438, doi:10.1094/PD-90-0433

Hillis DM, Huelsenbeck JP. 1992. Signal, noise and reliability in molecular phylogenetic analyses. J Hered 83:189-195.

Hodges CS, Alfenas AC, Ferreira FA. 1986. The conspecificity of Cryphonectria cubensis and Endothia eugeniae. Mycologia 78:343-350, doi:10.2307/3793037

Huelsenbeck JP, Bull JJ, Cunningham CW. 1996. Combining data in phylogenetic analysis. Trends Ecol Evol 11: 152-158, doi:10.1016/0169-5347(96)10006-9

Katoh K, Misawa K, Kuma K, Miyata T. 2002. MAFFT: a novel method for rapid multiple sequence alignment based on fast Fourier transform. Nucleic Acids Res 30: 3059-3066, doi:10.1093/nar/gkf436

Kobayashi T, Itô K. 1956. Two new species of Endothia. Ann Phytopathol Soc Japan 21:151-152.

Myburg H, Gryzenhout M, Wingfield BD, Milgroom MG, Shigeru K, Wingfield MJ. 2004. DNA sequence data and morphology define Cryphonectria species in Europe, China and Japan. Can J Bot 82:1730-1743, doi:10.1139/b04-135

— $-\longrightarrow$, Wingfield MJ. 2002. $\beta$-tubulin and Histone $\mathrm{H} 3$ gene sequences distinguish Cryphonectria cubensis from South Africa, Asia and South America. Can J Bot 80:590-596, doi:10.1139/b02-039

,,--- - - 2003. Conspecificity of Endothia eugeniae and Cryphonectria cubensis: a reevaluation based on morphology and DNA sequence data. Mycoscience 44:187-196.

— Wingfield BD, Wingfield MJ. 1999. Phylogeny of Cryphonectria cubensis and allied species inferred from DNA analysis. Mycologia 91:243-250, doi:10.2307/ 3761369

Nakabonge G, Gryzenhout M, Roux J, Wingfield BD, Wingfield MJ. 2006a. Celoporthe dispersa gen. et sp. nov. from native Myrtales in South Africa. Stud Mycol 55:255-267, doi:10.3114/sim.55.1.255

—_, Roux J, Gryzenhout M, Wingfield MJ. 2006b. Distribution of Chrysoporthe canker pathogens on Eucalyptus and Syzygium species in eastern and southern Africa. Plant Dis 90:734-740, doi:10.1094/PD-90-0734

Nylander JAA. 2004. MrModeltest 2.3. Program distributed by the author. Uppsala, Sweden: Evolutionary Biology Centre, Uppsala Univ.

Posada D, Crandall KA. 1998. Modeltest: testing the model of DNA substitution. Bioinformatics 14:817-818, doi:10.1093/bioinformatics/14.9.817 
Rayner RW. 1970. A mycological colour chart. Kew, Surrey, UK: Commonwealth Mycological Institute and British Mycological Society. 34 p.

Rehner SA, Samuels GJ. 1994. Taxonomy and phylogeny of Gliocladium analysed from nuclear large subunit ribosomal DNA sequences. Mycol Res 98:625-634, doi:10.1016/S0953-7562(09)80409-7

Rodas CA, Gryzenhout M, Myburg H, Wingfield BD, Wingfield MJ. 2005. Discovery of the Eucalyptus canker pathogen Chrysoporthe cubensis on native Miconia (Melastomataceae) in Colombia. Plant Path 54:460 470, doi:10.1111/j.1365-3059.2005.01223.x

Ronquist F, Huelsenbeck JP. 2003. MrBayes 3: Bayesian phylogenetic inference under mixed models. Bioinformatics 19:1572-1574, doi:10.1093/bioinformatics/ btg 180

SAS Institute Inc. 1999. SAS/STAT 8 users' guide. Cary, North Carolina: SAS Institute Inc.

Sharma JK, Mohanan C, Florence EJM. 1985. Occurrence of Cryphonectria canker disease of Eucalyptus in Kerala, India. Ann Appl Biol 106:265-276, doi:10.1111/j.17447348.1985.tb03116.x

Shear CL, Stevens NE. 1913. The chestnut blight parasite (Endothia parasitica) from China. Science 38:295-297, doi:10.1126/science.38.974.295

. 1916. The discovery of the chestnut blight parasite (Endothia parasitica) and other chestnut fungi in Japan. Science 43:173-176, doi:10.1126/science. 43.1101.173-a

Slippers B, Crous PW, Denman S, Coutinho TA, Wingfield BD, Wingfield MJ. 2004. Combined multiple gene genealogies and phenotypic characters differentiate several species previously identified as Botryosphaeria dothidea. Mycologia 96:83-101, doi:10.2307/3761991

, Stenlid J, Wingfield MJ. 2005. Emerging pathogens: Fungal host jumps following anthropogenic introduction. Trends Ecol Evol 20:420-421, doi:10.1016/ j.tree.2005.05.002
Swofford DL. 2002. PAUP* 4.0: phylogenetic analysis using parsimony (*and other methods). Sunderland, Massachusetts: Sinauer Associates.

Tamura K, Dudley J, Nei M, Kumar S. 2007. MEGA4: molecular evolutionary genetics analysis (MEGA) software. Mol Biol Evol 24:1596-1599, doi:10.1093/molbev/msm092

Teng SC. 1934. Notes on Sphaeriales from China. Sinensia 4:359-433.

van der Merwe NA, Gryzenhout M, Steenkamp ET, Wingfield BD, Wingfield MJ. 2010. Multigene phylogenetic and population differentiation data confirm the existence of a cryptic species within Chrysoporthe cubensis. Fungal Biol 114:966-979, doi:10.1016/j.funbio. 2010.09.007

Vermeulen M, Gryzenhout M, Wingfield MJ, Roux J. 2011. New records of Cryphonectriaceae from southern Africa including Latruncellus aurorae gen. sp. nov. Mycologia 103:554-569, doi:10.3852/10-283

Vilgalys R, Hester M. 1990. Rapid genetic identification and mapping of enzymatically amplified ribosomal DNA from several Cryptococcus species. J Bacteriol 172:4238-4246.

White TJ, Bruns T, Lee S, Taylor J. 1990. Amplification and direct sequencing of fungal ribosomal RNA genes for phylogenetics. In: Innis AM, Gelfand DH, Sninsky JJ, White TJ, eds. PCR protocols: a guide to methods and applications. San Diego: Academic Press. p 315-322.

Wingfield MJ. 2003. Increasing threat of diseases to exotic plantation forests in the southern hemisphere: lessons from Cryphonectria canker. Australas Plant Path 32: 133-139, doi:10.1071/AP03024

Zhang N, Blackwell M. 2001. Molecular phylogeny of dogwood anthracnose fungus (Discula destructiva) and the Diaporthales. Mycologia 93:355-365, doi:10.2307/3761657

Zhou X, Xie Y, Chen SF, Wingfield MJ. 2008. Diseases of eucalypt plantations in China: challenges and opportunities. Fungal Divers 32:1-7. 